\title{
Transmissão da variação da taxa de câmbio para os preços de exportação brasileiros do algodão
}

Transmission of exchange rate variation for the brazilian export prices of cotton

\author{
Leonardo Sangoi Copetti', Daniel Arruda Coronel", Adriano Mendonça Souza'II
}

\begin{abstract}
RESUMO
O objetivo desta pesquisa consistiu no exame da relação entre as variações cambiais e os preços de exportação brasileiros do algodão, relação definida como o pass-through da taxa de câmbio, tendo como referência o período de junho de 1999 a dezembro de 2018. Os dados foram coletados nos sites do Centro de Estudos Avançados em Economia Aplicada - CEPEA, no Instituto de Economia Aplicada IPEA e na Intercontinental Exchange - ICE. Neste sentido, fez-se uso dos instrumentais de séries temporais, especialmente do Modelo Vetor de Correção de Erros. Os resultados encontrados forneceram indicações de que o grau de pass-through da taxa de câmbio para os preços de exportação do algodão ocorreram de forma incompleta no período total e no primeiro subperíodo e nula no segundo subperíodo, representando que depreciações da taxa de câmbio não se traduzem em ganhos significativos de competitividade, uma vez que não reduzem expressivamente os preços de exportação.
\end{abstract}

Palavras-chave: Algodão. Preços de Exportação. Pass-Through.

\begin{abstract}
The aim of this research exam the relation between exchange rate variations and the Brazilian export prices of cotton, relation defined as pass-through of exchange rate, having as reference the period from June, 1999 to December, 2018. The data was collected from the sites of the Center for Advanced Studies in Applied Economics - CEPEA, in the Institute for Applied Economics - IPEA and in the Intercontinental Exchange - ICE. In this sense, we used time series analysis, especially the Vector Error Correction Model. The results provided indications that the degree of pass-through of the exchange rate for the export prices of cotton occurred in an incomplete way in the total period and in the first sub-period and null (zero) in the second sub-period, representing that depreciations of the exchange rate do not translate themselves in significant gains of competitiveness, since that they do not reduce expressively the export prices.
\end{abstract}

Keywords: Cotton; Export Prices; Pass-Through.

\footnotetext{
'Universidade Federal de Santa Maria, Brasil; e-mail: leonardocopetti@hotmail.com;

" Universidade Federal de Santa Maria. Brasil. e-mail: daniel.coronel@uol.com.br;

III Universidade Federal de Santa Maria. Brasil. e-mail: amsouza.sm@gmail.com
} 


\section{INTRODUÇÃO}

Segundo o United States Department of Agriculture - USDA (2019), o Brasil é o segundo maior exportador mundial de algodão, visto que, na safra 2018/ 2019, o total exportado foi de 1,31 milhões de toneladas, o que representou $14,57 \%$ das exportações mundiais, que foram de 9 milhões de toneladas.

Segundo o Ministério do Desenvolvimento, Indústria e Comércio Exterior (MDIC, 2019), o total de algodão exportado pelo Brasil, em 2018, foi de US\$1,59 bilhões, o que representou $0,66 \%$ das exportações totais do país. Em comparação com o ano de 1999, houve um incremento de $34.541 \%$ do faturamento das exportações desta commodity, sendo que as exportações neste ano foram de US\$4,59 milhões. Ainda, os dez principais países de destino do algodão brasileiro, representando uma média de 75\% das exportações, de 1999 a 2018, foram China (15\%), Indonésia (14\%), Coreia do Sul (10\%), Argentina (9\%), Vietnã (7\%), Paquistão (6\%), Turquia (6\%), Tailândia (4\%), Malásia (3\%) e Taiwan (3\%). Além disso, segundo a Word Trade Organization - WTO (2019), dentre esses dez maiores importadores, a Argentina é a que aplica as maiores barreiras à importação de algodão $(21,74 \%)$ e a Tailândia é a que aplica as menores taxas, de $4,55 \%$.

Para o USDA (2019), os três maiores exportadores de algodão, na safra 2018/2019, foram, respectivamente, Estados Unidos, com 3,22 milhões de toneladas (35,76\%); Brasil, com 1,31 milhões de toneladas (14,57\%) e Austrália, com 792 mil toneladas $(8,80 \%)$. Já os três maiores importadores mundiais foram, respectivamente, China, com 2,13 milhões de toneladas (22,73\%); Bangladesh, com 1,59 milhões de toneladas $(16,97 \%)$ e Vietnã, com 1,54 milhões de toneladas $(16,44 \%)$. Além disso, segundo a WTO (2019), dentre esses três maiores importadores, Bangladesh é o que aplica as maiores barreiras à importação de algodão (17,2\%), o Vietnã aplica um percentual médio de tarifas de importação, de 9,38\%, e a China aplica taxas de importação de 8,95\% a commodity.

Segundo Obstfeld e Rogoff (1995), as políticas macroeconômicas consideradas ótimas para uma região dependem, dentre outros fatores, de como os exportadores definem seus preços, se o fixam com base na sua própria moeda (Producer Currency Pricing - PCP), ou com base na moeda do mercado de destino de seu produto (Local 
Currency Pricing - LCP), sendo que esta escolha influencia o ambiente macroeconômico através do grau de repasse cambial (pass-through) aos preços. Desta forma, no caso de PCP, uma depreciação cambial produz a redução no preço na moeda de destino das exportações, aumentando a quantidade demandada, e no caso de LCP, uma depreciação cambial produz a elevação do mark-up do exportador, sem que a quantidade demandada se altere.

Além disso, outro ponto de relevância na determinação do grau de passthrough cambial é a percepção dos exportadores sobre se as mudanças da taxa de câmbio são transitórias ou permanentes. Para Tejada e Silva (2008), a mudança na taxa de câmbio percebida como transitória terá pouco efeito na determinação dos preços de exportação; por outro lado, a maior confiabilidade na previsão da taxa de câmbio futura relaciona-se a um efeito maior nos preços de exportação e o repasse da variação cambial é feito integralmente aos preços.

Na literatura econômica, diversos estudos apresentam uma influência parcial das variações cambiais sobre os preços de exportação do país, representando o passthrough incompleto, no contexto nacional. Destacam-se as pesquisas realizadas por Ferreira; Sansó (1999), Cruz Jr. ; Silva (2004), Tejada ; Silva (2008), Fraga et al. (2008), Correa (2012), Copetti; Vieira ; Coronel (2012), Vieira ; Coronel (2013), Souza (2018), Souza; Raniro ; Rosa (2018).

Os países que fizeram tardiamente seu processo de industrialização como o Brasil são geralmente considerados com pouco controle sobre os preços que vendem nos mercados internacionais (FERREIRA; SANSÓ, 1999). Desta forma, as variações na taxa câmbio podem ter pouca relevância na determinação dos preços de exportação, pois o coeficiente de pass-through tende a ser nulo.

Seguindo esta temática, o problema de pesquisa é responder se existe diferença entre o grau de pass-through para os preços de exportação brasileiros do algodão no período total de 06/1999 a 12/2018, e nos subperíodos de 06/1999 a 06/2009 e $07 / 2009$ a $12 / 2018 ?$

A partir do desenvolvimento deste estudo, têm-se elementos para auxiliar na compreensão da magnitude com que as variações cambiais são transmitidas aos preços do algodão, bem como para entender mais sobre as estratégias de preço 
adotadas pelos exportadores brasileiros e sobre como a política econômica e cambial pode impactar sua competitividade. Além disso, o presente estudo diferencia-se dos demais realizados pela análise em subperíodos e adiciona a literatura de competitividade pela escassez de estudos sobre o mercado do algodão e coeficiente de pass-through, sendo encontrado, na literatura nacional e internacional, somente o trabalho de Souza (2018).

Freitas, Fossati \& Nicola (2005) realizaram uma pesquisa sobre a competitividade internacional do Brasil no comércio das commodities negociadas na BM\&F e do algodão, no período de 1990 a 2003. Para tanto, utilizaram o Índice de Vantagem Comparativa Revelada (IVCR), Vantagem Relativa na Exportação (VRE) e Competitividade Revelada (CR). Como resultados, constatou-se que as exportações brasileiras de algodão foram competitivas nos anos de 1990, 1991, 2001, 2002 e 2003.

Já Bessa \& Amin (2009), analisaram o comportamento das exportações do algodão em pluma brasileiro no comparativo com seus principais concorrentes (Estados Unidos, Austrália e a Índia) utilizando a metodologia Market Share Analysis, no período de 1989 e 2004. Como resultados, tem-se que o efeito dimensão foi negativo durante toda década de 1990, indicando que o Brasil teve dificuldades em colocar seu excedente de produção no comércio internacional, o que não ocorreu de 2001 a 2004, pois, neste período, o país reduziu suas importações e conseguiu exportar com maior facilidade para o mercado mundial; o efeito distribuição foi negativo de 1989 a 2004, demonstrando que o Brasil concentrou suas exportações em países que indicavam pouco crescimento nas importações mundiais deste produto; e o efeito competição foi positivo, indicando aumento da competitividade; desta forma, o país conseguiu manter a sua posição competitiva no mercado internacional do algodão em pluma diante dos seus principais concorrentes de 2001 a 2004.

Ainda nesta perspectiva, Maia Neto (2013) analisou o mercado do algodão brasileiro entre 1990 a 2012 utilizando um conjunto de indicadores de concentração de mercado e competitividade, dentre eles Gini Locacional (GL), Quociente Locacional (QL), Coeficiente Gini-Hirschman (IC), Índice de Comércio Intrassetorial (IIS), Índice de Hirschman-Herfindahl $(\mathrm{IHH})$, Índice de Gini, e IVCR. Como resultados, o Brasil apresentou competitividade nos anos de 2001 e entre os anos de 2003 a 2011. 
Além disso, a competitividade das exportações brasileiras de algodão também foi analisada pelos autores Copetti e Coronel $(2018,2019)$. Por outro lado, percebe-se uma lacuna de estudos envolvendo competitividade do algodão brasileiro e o coeficiente de pass-through, para o que a presente pesquisa vem a contribuir.

Por fim, os resultados desta pesquisa poderão servir de subsídios para políticas de comércio exterior visando aumentar a competitividade e maior inserção do setor. O presente trabalho está estruturado em quatro seções, além desta introdução. $\mathrm{Na}$ segunda seção, apresenta-se a participação do Brasil no mercado internacional do algodão; na terceira, são apresentados os estudos empíricos realizados sobre a transmissão de preços e o coeficiente de pass-through no mercado brasileiro; na quarta seção, os procedimentos metodológicos são esboçados; na seção seguinte, os resultados são analisados e discutidos; e por fim, na última seção, são apresentadas as principais conclusões do trabalho.

\section{PARTICIPAÇÃO DO BRASIL NO MERCADO INTERNACIONAL DO ALGODÃO}

Segundo o United States Department of Agriculture (USDA, 2019), o Brasil foi o quarto maior produtor e segundo maior exportador mundial de algodão, na safra 2018/2019, quando o país produziu 2,780 milhões de toneladas do produto, representando $10,71 \%$ da produção mundial, que foi de 25,945 milhões de toneladas. Do total produzido pelo mundo, cerca de 9 milhões de toneladas foram destinadas à exportação, sendo que o Brasil destinou 1,31 milhões de toneladas ao mercado externo, assumindo a segunda posição entre os maiores exportadores mundiais. A Tabela 1 ilustra as participações dos maiores produtores de algodão nas safras agrícolas 1999/2000 e 2018/2019. 
Tabela 1 - Participação dos maiores produtores mundiais de algodão entre as safras 1999/2000 e 2018/2019

\begin{tabular}{|c|c|c|c|c|c|}
\hline \multirow[b]{2}{*}{ País } & \multicolumn{2}{|c|}{$1999 / 2000$} & \multicolumn{2}{|c|}{$2018 / 2019$} & \multirow[b]{2}{*}{$\begin{array}{c}\text { Variação da } \\
\text { participação } \\
\text { (em p.p.) }\end{array}$} \\
\hline & $\begin{array}{l}\text { Produção } \\
\text { (milhões de } \\
\text { toneladas) }\end{array}$ & $\begin{array}{c}\text { Participação } \\
\text { (\%) }\end{array}$ & $\begin{array}{l}\text { Produção } \\
\text { (milhões de } \\
\text { toneladas) }\end{array}$ & $\begin{array}{c}\text { Participação } \\
\text { (\%) }\end{array}$ & \\
\hline China & 3,837 & 20,02 & 6,050 & 23,32 & 3,30 \\
\hline Índia & 2,655 & 13,86 & 5,777 & 22,27 & 8,41 \\
\hline \multicolumn{6}{|l|}{ Estados } \\
\hline Unidos & 3,699 & 19,30 & 4,004 & 15,43 & $-3,87$ \\
\hline Brasil & 0,701 & 3,66 & 2,780 & 10,71 & 7,05 \\
\hline Paquistão & 1,913 & 9,98 & 1,657 & 6,39 & $-3,60$ \\
\hline Turquia & 0,792 & 4,13 & 0,807 & 3,11 & $-1,02$ \\
\hline Uzbequistão & 1,129 & 5,89 & 0,714 & 2,75 & $-3,14$ \\
\hline Austrália & 0,754 & 3,93 & 0,480 & 1,85 & $-2,09$ \\
\hline México & 0,146 & 0,76 & 0,378 & 1,46 & 0,70 \\
\hline Grécia & 0,441 & 2,30 & 0,307 & 1,18 & $-1,11$ \\
\hline \multicolumn{6}{|l|}{ Resto do } \\
\hline Mundo & 3,097 & 16,16 & 2,992 & 11,53 & $-4,63$ \\
\hline Total & 19,164 & 100,00 & 25,945 & 100,00 & - \\
\hline
\end{tabular}

Com base na Tabela 1, percebe-se que o incremento na produção de algodão no mundo, nas safras de 1999/2000 e 2018/2019, foi de 38,38\%, passando de 19,164 para 25,945 milhões toneladas, sendo que o Brasil teve um aumento de $297 \%$ no total produzido e 7,05\% na participação de mercado. O país que mais ganhou participação de mercado no período analisado foi a Índia (8,41\%), passando de 13,86\% para $22,27 \%$, e assumindo a segunda posição de maior produtor na safra 2018/2019, fato decorrente principalmente da introdução do algodão transgênico a partir de 2002, que aumentou a produtividade de 30 a 60\% (USDA, 2009).

A seguir, na Tabela 2, é avaliada a participação dos principais exportadores mundiais de algodão com base nos mesmos períodos. 
Tabela 2 - Participação dos maiores exportadores mundiais de algodão entre as safras 1999/2000 e 2018/2019

\begin{tabular}{|c|c|c|c|c|c|}
\hline \multirow[b]{2}{*}{ País } & \multicolumn{2}{|c|}{$1999 / 2000$} & \multicolumn{2}{|c|}{$2018 / 2019$} & \multirow{2}{*}{$\begin{array}{c}\text { Variação da } \\
\text { participação } \\
\text { (em p.p.) }\end{array}$} \\
\hline & $\begin{array}{c}\text { Exportação (milhões } \\
\text { de toneladas) }\end{array}$ & $\begin{array}{c}\text { Participação } \\
(\%)\end{array}$ & $\begin{array}{c}\text { Exportação (milhões } \\
\text { de toneladas) }\end{array}$ & $\begin{array}{c}\text { Participação } \\
(\%)\end{array}$ & \\
\hline \multicolumn{6}{|l|}{ Estados } \\
\hline Unidos & 1,472 & 24,88 & 3,218 & 35,76 & 10,88 \\
\hline Brasil & 0,003 & 0,04 & 1,311 & 14,57 & 14,52 \\
\hline Austrália & 0,700 & 11,84 & 0,792 & 8,80 & $-3,04$ \\
\hline Índia & 0,015 & 0,26 & 0,763 & 8,48 & 8,22 \\
\hline Benim & 0,142 & 2,40 & 0,305 & 3,39 & 0,99 \\
\hline Grécia & 0,235 & 3,98 & 0,295 & 3,28 & $-0,70$ \\
\hline Mali & 0,196 & 3,32 & 0,294 & 3,27 & $-0,05$ \\
\hline Burkina & 0,113 & 1,92 & 0,205 & 2,28 & 0,36 \\
\hline \multicolumn{6}{|l|}{ Costa do } \\
\hline Marfim & 0,160 & 2,71 & 0,195 & 2,17 & $-0,54$ \\
\hline Uzbequistão & 0,916 & 15,48 & 0,131 & 1,45 & $-14,03$ \\
\hline \multicolumn{6}{|l|}{ Resto do } \\
\hline Mundo & 1,962 & 33,17 & 1,478 & 16,42 & $-16,75$ \\
\hline Total & 5,913 & 100,00 & 9,000 & 100,00 & - \\
\hline
\end{tabular}

Nota: Ranking relacionado à safra de 2018/2019

Fonte: Elaborado pelos autores a partir de USDA (2019)

O comércio mundial de algodão é dominado, em grande parte, pelos Estados Unidos, que, na safra de 2018/2019, tiveram uma participação de 35,76\% no total exportado, seguido por Brasil, Austrália e Índia, com, respectivamente, 14,57\%, 8,80\%, e 8,48\%. Neste cenário, o maior ganho de participação foi o brasileiro, passando de 0,04\%, na safra de 1999/2000, a 14,57\% na safra de 2018/2019, fato ligado ao crescimento do mercado internacional, aos ganhos de lucratividade dos exportadores pela depreciação cambial, à elevação da produção da produção (297\%) e da produtividade, que passou de 0,93 ton/ha, na safra de 1999/2000, a 1,72 ton/ha, na safra de 2018/2019, decorrente do melhoramento genético e da aplicação de técnicas adequadas no manejo da Cultura (ABRAPA, 2017 ; USDA, 2018). Em relação aos demais concorrentes no comércio internacional do algodão, perceberam-se, entre as safras 1999/2000 e 2018/2019, as seguintes alterações na participação de mercado: crescimento em Benin (0,99\%) e Burquina (0,36\%); e redução na Grécia $(0,70 \%)$, Mali $(0,05)$, Costa do Marfim $(0,54)$ e Uzbequistão $(14,03)$. A média do total de algodão disponível brasileiro, entre as safras de 1999/2000 a 2018/2019, foi de 2,61 milhões de toneladas, e, destes, no período total, 20\% foram destinados à exportação, 33\%, ao consumo interno e $48 \%$ foram os estoques finais; no subperíodo 01 (06/199906/2009), 13\% foram destinados à exportação, 43\%, ao consumo interno e 44\% foram 
os estoques finais; e, no subperíodo 02 (07/2009-12/2018), 24\% foram destinados à exportação, 26\%, ao consumo interno e 51\% foram os estoques finais (USDA, 2019). Percebe-se a alta participação dos estoques finais que está relacionada principalmente ao período da coleta de dados do departamento americano em julho do corrente ano, quando os estoques finais e iniciais estão no auge. Porém, as representatividades estão em consonância com dados da Companhia Nacional de Abastecimento (CONAB, 2019), indicando a orientação ao mercado interno. Além disso, a produção brasileira de algodão é distribuída pelas regiões do país, tomando como base a safra 2018/2019, da seguinte forma: 0,96\% Norte, 23,35\% Nordeste, 72,44\% Centro-Oeste, 3,21\% Sudeste e 0,04\% Sul (CONAB, 2019). Com base neste levantamento, percebe-se a alta concentração do algodão produzido pelo país na Região Centro-Oeste.

\section{TRANSMISSÃO DE PREÇOS E COEFICIENTE DE PASS-THROUGH NO MERCADO BRASILEIRO}

Ferreira e Sansó (1999) investigaram a relação da taxa de câmbio e os preços das exportações brasileiras de manufaturados, com dados trimestrais, no período de março de 1978 a abril de 1996, dividido em dois subperíodos, de março de 1978 a abril de 1985 e de janeiro de 1986 a abril de 1996. Para tanto, utilizaram-se de econometria de séries temporais baseadas na metodologia de Engle-Granger, Shin e Johansen. Como resultados, no período de março de 1978 a abril de 1996, os autores encontraram um coeficiente de pass-through incompleto e verificaram que as variações da taxa de câmbio influenciam parcialmente os preços de exportação. Já no subperíodo de janeiro de 1986 a abril de 1996, o pass-though foi próximo a zero, indicando que as variações na taxa de câmbio possivelmente não exerceram influência sobre os preços das exportações brasileiras de manufaturados, sendo as mudanças nos preços de exportação explicadas basicamente pelo movimento nos preços internacionais. Os autores sugerem que este resultado está ligado à opção dos exportadores brasileiros por não alterarem seus preços em moeda estrangeira, devido à extrema instabilidade cambial que caracterizou este período. Para preservar sua participação nos mercados externos, os exportadores optaram por manter seus 
preços em moeda estrangeira invariantes às mudanças na taxa de câmbio que são percebidas como transitórias.

Cruz Jr. \& Silva (2004) estudaram o coeficiente de pass-through para a exportação trimestral dos produtos agropecuários brasileiros no período compreendido do $3^{\circ}$ trimestre de 1994 ao $2^{\circ}$ trimestre 2003. Foram utilizadas as seguintes séries para a estimação do modelo: o índice de preços de exportação para produtos agropecuários do Brasil, o índice de preços de atacado para lavouras de exportação (IPA-OG) como proxy para o custo de produção, a taxa de câmbio nominal (real/dólar) fim do período, e, para o preço internacional, foi utilizada a série de preços de importação de commodities dos Estados Unidos. Os autores utilizaram-se de econometria de séries temporais e do modelo Vetorial de Correção de Erros - VEC. Como resultado, os autores estimaram um coeficiente de pass-through de -0,53, representando que as variações da taxa de câmbio afetam parcialmente o preço de exportação dos produtos agropecuários brasileiros. Tejada e Silva (2008) analisaram a relação entre as variações da taxa de câmbio e os preços das exportações dos principais produtos exportados pelo Brasil, com dados trimestrais, de janeiro de 1980 a janeiro de 2004. Os setores pesquisados e as respectivas participações no ano de 2004 foram Peças e Outros Veículos (10,29\%), Siderurgia (7,11\%), Extrativa Mineral (8,41\%), Máquinas e Tratores - MAQ (5,33\%), Veículos Automotores (5,05\%), Óleos Vegetais (4,96\%), Refino de Petróleo (4,55\%), Madeira e Mobiliário (4,14\%), Beneficiamento de Produtos Vegetais (3,22\%), Metalurgia de Não Ferrosos (3,16\%), Celulose Papel e Gráfica (3,06\%), Material Elétrico (2,34\%), Elementos Químicos (2,15\%), e Equipamentos Eletrônicos (2,10\%). Para estimar o coeficiente de passthrough, os autores utilizaram o filtro de Kalman, gerando um coeficiente variável ao longo do tempo. Como resultados, os setores analisados apresentaram um coeficiente de pass-through oscilando entre zero e -1 (menos um), indicando passthrough incompleto, ou seja, a variação da taxa de câmbio afeta parcialmente os preços de exportação. Fraga et al. (2008) investigaram o repasse da variação da taxa de câmbio para os preços mensais de exportação da soja em grão do Brasil no período de julho de 1994 a dezembro de 2004. Para tanto, os autores utilizaram testes de raiz unitária (ADF), de co-integração de Johansen e o Modelo Vetorial de 
Correção de Erros (VEC). Os resultados indicaram um coeficiente de pass-through no valor de -0,34, representando um pass-through incompleto, ou seja, que as variações da taxa de câmbio não se traduzem em ganhos significativos de competitividade, afetando apenas o mark-up do exportador. Correa (2012) analisou o impacto das variações cambiais sobre as exportações de 26 setores da economia brasileira, no período de 1995 a 2005. Os setores pesquisados foram extrativa mineral, extração de petróleo e gás, minerais não metálicos, siderurgia, metalurgia dos não ferrosos, outros produtos metalúrgicos, fabricação de máquinas e tratores, material elétrico, equipamentos eletrônicos, automóveis, outros veículos e peças, madeira e mobiliário, papel e gráfica, indústria da borracha, elementos químicos não petroquímicos, refino de petróleo e petroquímica, fabricação de produtos químicos diversos, indústria têxtil, fabricação de artigos de couro e calçados, indústria do café, beneficiamento de produtos vegetais, abate de animais, indústria do açúcar, fabricação de gorduras e óleos vegetais, outros produtos alimentares e bebidas, e indústrias diversas. As variáveis utilizadas no modelo econométrico foram o preço das exportações brasileiras de 26 setores classificados pelo Instituto Brasileiro de Geografia e Estatística - IBGE, a taxa de câmbio nominal, o custo doméstico utilizando uma metodologia para custo setorial, o preço das exportações concorrentes internacionais correspondendo ao índice de preços das importações norte-americanas e o grau de utilização da capacidade instalada calculada pela Fundação Getúlio Vargas - FGV. Como resultados, os autores concluíram coeficientes de pass-through incompletos para os diversos setores pesquisados.

Copetti, Vieira \& Coronel (2012) realizaram pesquisa sobre a transmissão da variação da taxa de câmbio aos preços de exportação do grão de soja no Brasil e na Argentina, no período de 03/1999 a 02/2011. Para tanto, utilizam-se de econometria de séries temporais e do modelo Vetorial de Correção de Erros - VEC. Os resultados revelaram um coeficiente de pass-through incompleto para o Brasil $(-0,11)$ e nulo para Argentina. No mercado brasileiro, a estimativa do coeficiente indicou que a variação da taxa de câmbio exerce influência parcial sobre os preços médios de exportação do grão de soja, ou seja, a variação de $1 \%$ na taxa de câmbio é repassada $0,11 \%$ no mesmo sentido para o preço médio de exportação do grão de soja no Brasil. Já para o 
mercado argentino, as variações da taxa de câmbio não exercem influência sobre os preços médios de exportação do grão de soja. Outro estudo desenvolvido pelos autores Copetti, Vieira \& Coronel (2013) analisou o relacionamento da taxa de câmbio (real/ euro - $\mathrm{R} \$ / €$ ) e os preços de exportação do grão de soja entre Estados Unidos, Brasil e Argentina (em euro/ toneladas - €/ toneladas), no período de janeiro de 2003 a janeiro de 2012. Para tanto, os autores usaram testes de estacionariedade das séries (ADF e KPSS), o teste de cointegração de Johansen e o modelo Vetorial de Correção de Erros - VEC. Como resultados, foram identificados um coeficiente de pass-through incompleto para os Estados Unidos e coeficientes nulos para o Brasil e Argentina. No mercado norte-americano, o coeficiente de $-0,65$ indicou influência parcial da variação na taxa de câmbio (dólar/ euro - US\$/€) sobre o preço de exportação do grão de soja (€/ toneladas), e uma variação de $0,65 \%$ no mesmo sentido do preço de exportação do grão de soja produzida pela variação de $1 \%$ na taxa de câmbio. Já nos mercados brasileiros e argentinos, a variação da taxa de câmbio não exerce influência sobre os preços de exportação do grão de soja.

Souza (2018) buscou avaliar a influência das variações cambiais no desempenho exportador do milho e do algodão considerando dados mensais de janeiro de 2002 a dezembro de 2016. Para estimar o pass-through da taxa de câmbio para os preços de exportação do milho e do algodão, o autor empregou o Modelo Vetorial de Correção de Erros. Os resultados mostraram que o pass-through da taxa de câmbio para o preço de exportação do milho foi incompleto no valor de 0,419, implicando que as variações cambiais afetaram a competitividade do exportador dessa cultura, e também, no mesmo modelo, apresentou um coeficiente inelástico para o preço internacional do milho no valor de -0,507. No caso do algodão, o passthrough para o preço de exportação do algodão foi nulo, indicando que as variações cambiais agiram impactando apenas o mark-up do exportador dessa commodity, custo de produção nulo e coeficiente inelástico $(-0,847)$ na transmissão dos preços internacionais do algodão ao mercado doméstico. Souza, Raniro e Rosa (2018) avaliaram o pass-through da taxa de câmbio para os preços de exportações, em dólares e em reais, do açúcar brasileiro de janeiro de 2012 a dezembro de 2016. Os autores utilizaram as ferramentas econométricas de séries temporais multivariadas, 
com destaque para o Modelo Vetorial de Correção de Erro. Os resultados apontaram um pass-through incompleto da taxa de câmbio para os preços de exportações do açúcar, em dólares e em reais, tendo baixo coeficiente $(-0,03)$ de pass-through cambial para o preço em dólares e alto coeficiente $(0,97)$ para o preço em reais. No Quadro 1, faz-se uma síntese dos estudos acerca dos estudos sobre transmissão de preços e coeficiente de pass-through nas exportações brasileiras.

Quadro 1 - Síntese dos estudos empíricos

\begin{tabular}{|c|c|c|c|c|c|}
\hline Autores & $\begin{array}{l}\text { País / } \\
\text { países }\end{array}$ & Período & Produtos & $\begin{array}{c}\text { Metodologia/ } \\
\text { objetivo do estudo }\end{array}$ & Resultados \\
\hline $\begin{array}{l}\text { Ferreira } \\
\text { e Sansó } \\
(1999)\end{array}$ & Brasil & $\begin{array}{l}03 / 1978- \\
04 / 1996\end{array}$ & $\begin{array}{c}\text { produtos } \\
\text { manufaturados }\end{array}$ & $\begin{array}{c}\text { Metodologia de Engle-Granger, } \\
\text { Shin e Johansen/ coeficiente de } \\
\text { pass-through }\end{array}$ & $\begin{array}{l}\text { pass-through } \\
\text { incompleto }\end{array}$ \\
\hline $\begin{array}{l}\text { Cruz Jr. } \\
\& \text { Silva } \\
(2004)\end{array}$ & Brasil & \begin{tabular}{|c|}
$3^{\circ}$ trim./ \\
- \\
$2^{\circ}$ trim./ 2003
\end{tabular} & $\begin{array}{c}\text { produtos } \\
\text { agropecuários }\end{array}$ & $\begin{array}{c}\text { Modelo Vetorial de Correção de } \\
\text { Erros/coeficiente de } \\
\text { pass-through }\end{array}$ & $\begin{array}{c}\text { pass-through } \\
\text { incompleto }(-0,53)\end{array}$ \\
\hline $\begin{array}{l}\text { Tejada e } \\
\text { Silva } \\
(2008)\end{array}$ & Brasil & $\begin{array}{c}01 / 1980- \\
01 / 2004\end{array}$ & $\begin{array}{l}\text { exportações } \\
\text { setoriais }\end{array}$ & $\begin{array}{l}\text { filtro de Kalman/coeficiente de } \\
\text { pass-through }\end{array}$ & $\begin{array}{c}\text { pass-through } \\
\text { incompleto (entre -1 } \\
\text { e zero) }\end{array}$ \\
\hline $\begin{array}{l}\text { Fraga et } \\
\text { al. (2008) }\end{array}$ & Brasil & $\begin{array}{c}07 / 1994- \\
12 / 2004\end{array}$ & grão de soja & $\begin{array}{c}\text { Modelo Vetorial de Correção de } \\
\text { Erros/coeficiente de pass- } \\
\text { through }\end{array}$ & $\begin{array}{c}\text { pass-through } \\
\text { incompleto }(-0,34)\end{array}$ \\
\hline $\begin{array}{l}\text { Correa } \\
(2012)\end{array}$ & Brasil & $\begin{array}{c}1995- \\
2005\end{array}$ & $\begin{array}{l}\text { exportações } \\
\text { setoriais }\end{array}$ & $\begin{array}{c}\text { Econometria de series } \\
\text { temporais/ coeficiente de pass- } \\
\text { through }\end{array}$ & $\begin{array}{c}\text { pass-through } \\
\text { incompletos para os } \\
\text { setores pesquisados }\end{array}$ \\
\hline $\begin{array}{l}\text { Copetti, } \\
\text { Vieira \& } \\
\text { Coronel } \\
(2012) \\
\end{array}$ & $\begin{array}{l}\text { Brasil e } \\
\text { Argentina }\end{array}$ & $\begin{array}{c}03 / 1999- \\
02 / 2011\end{array}$ & grão de soja & $\begin{array}{l}\text { Modelo Vetorial de Correção de } \\
\text { Erros/coeficiente de pass- } \\
\text { through }\end{array}$ & $\begin{array}{c}\text { pass-through } \\
\text { incompleto }(-0,11)\end{array}$ \\
\hline \begin{tabular}{|l} 
Copetti, \\
Vieira \& \\
Coronel \\
$(2013)$ \\
\end{tabular} & $\begin{array}{l}\text { Estados } \\
\text { Unidos, } \\
\text { Brasil e } \\
\text { Argentina }\end{array}$ & $\begin{array}{c}01 / 2003- \\
01 / 2012\end{array}$ & grão de soja & $\begin{array}{l}\text { Modelo Vetorial de Correção de } \\
\text { Erros/coeficiente de pass- } \\
\text { through }\end{array}$ & pass-through nulo \\
\hline $\begin{array}{l}\text { Souza } \\
(2018)\end{array}$ & Brasil & $\begin{array}{c}01 / 2002- \\
12 / 2016\end{array}$ & $\begin{array}{l}\text { milho e } \\
\text { algodão }\end{array}$ & $\begin{array}{l}\text { Modelo Vetorial de Correção de } \\
\text { Erros/Modelo Estrutural } \\
\text { Vetorial de Correção de Erro/ } \\
\text { coeficiente de pass-through }\end{array}$ & $\begin{array}{c}\text { pass-through } \\
\text { incompleto para o } \\
\text { milho }(0,419) / \text { pass- } \\
\text { through nulo para o } \\
\text { algodão, custo de } \\
\text { produção nulo e } \\
\text { preço internacional } \\
\text { inelástico }(-0,847) \\
\end{array}$ \\
\hline $\begin{array}{l}\text { Souza, } \\
\text { Raniro e } \\
\text { Rosa } \\
(2018)\end{array}$ & Brasil & $\begin{array}{l}01 / 2012- \\
12 / 2016\end{array}$ & açúcar & $\begin{array}{l}\text { Modelo Vetorial de Correção de } \\
\text { Erros/coeficiente de pass- } \\
\text { through }\end{array}$ & $\begin{array}{c}\text { baixo coeficiente (- } \\
0,03) \text { de pass-through } \\
\text { cambial para os } \\
\text { preços em dólares e } \\
\text { alto coeficiente }(0,97) \\
\text { para o preço em } \\
\text { reais }\end{array}$ \\
\hline
\end{tabular}


Nesta subseção, foram reunidos estudos realizados sobre transmissão de preços e coeficiente de pass-through nas exportações brasileiras a fim de analisar a relação entre a taxa de câmbio e os preços de exportação do Brasil, bem como a transmissão de preços internacionais aos preços domésticos e de exportação brasileiros do algodão.

Os estudos supracitados revelaram que o Brasil apresentou um coeficiente de pass-through incompleto nas exportações (entre zero e -1 ou entre zero e 1) e nulo e que as transmissões de preços internacionais do algodão aos preços domésticos se comportaram de forma inelástica, ou seja, os preços internacionais são transmitidos parcialmente aos preços domésticos. A presente pesquisa difere dos estudos citados pelo comparativo do coeficiente de pass-through nas exportações do algodão na análise em subperíodos.

\section{METODOLOGIA}

\subsection{Modelo analítico}

O modelo econométrico pass-through, de acordo com Menon (1995), usado em sua forma mais simples, parte de um modelo de mark-up que pode ser representado da seguinte forma:

$$
P^{*} X=(1+\lambda)(C P / E)
$$

em que $P * X$ é o preço de exportação em moeda estrangeira; $(C P / E)$ é custo de produção, medido em moeda estrangeira; $E$ é a taxa de câmbio nominal; e $\lambda$ é markup. Partindo-se do pressuposto de que o mark-up pode variar de acordo com a pressão competitiva no mercado mundial, tem-se que:

$$
(1+\lambda)=\left[\frac{P W}{C P / E}\right]^{\alpha}
$$

Com: $[P W /(C P / E)]$ correspondendo à diferença entre o preço das exportações mundiais e o custo de produção do exportador medido em moeda estrangeira. 
Substituindo a Equação (2) em (1) e aplicando-se o logaritmo neperiano no resultado dessa substituição, chega-se à seguinte equação de preço de exportação em moeda estrangeira:

$$
\ln P^{*} X=(1+\alpha) \ln (C P / E)+\alpha \ln P W
$$

Considerando-se a versão não restrita da Equação (3), na qual não se exige que a soma dos coeficientes relativos a $\ln (C P / E)$ e $\ln (P W)$ seja igual a 1 e na qual se admite que os coeficientes relativos a $\ln (C P)$ e $\ln (E)$ difiram em sinal e magnitude, conforme Menon (1995), tem-se:

$$
\ln P^{*} X=\phi_{0}+\phi_{1} \ln C P+\phi_{2} \ln E+\phi_{3} \ln P W
$$

em que o coeficiente de pass-through é representado por $\Phi_{2}$.

A análise do resultado deste coeficiente pode ser expressa da seguinte forma:

1. $\Phi_{2}=0$; significa que a taxa de câmbio não exerce influência sobre o preço em moeda estrangeira dos bens exportados;

2. $\Phi_{2}=-1$ ou 1 ; significa que a mudança na taxa de câmbio afeta integralmente o preço em moeda estrangeira dos bens exportados; e

3. $-1<\Phi_{2}<0$ ou $0<\Phi_{2}<1$; significa que a mudança na taxa de câmbio afeta parcialmente o preço em moeda estrangeira dos bens exportados.

\subsection{Procedimentos econométricos}

\subsubsection{Teste de raiz unitária}

Para determinar a ordem de integração das séries de interesse, este trabalho utilizou os testes de raiz unitária Dickey-Fuller Aumentado (DICKEY; FULLER, 1979, 1981) e Kwiatkowski, Phillips, Schmidt e Shin (KPSS, 1992). Esses testes permitem verificar a existência ou não de raízes unitárias nas séries temporais, ou seja, se as variáveis são ou não estacionárias ${ }^{1} .0$ teste $A D F$ consiste na estimação da seguinte

\footnotetext{
1 Um processo estocástico é estacionário quando a sua média e a sua variância são constantes ao longo do tempo e quando o valor da covariância entre dois períodos de tempo depende apenas da distância, do intervalo ou da defasagem entre os períodos de tempo, e não do próprio tempo em que a covariância é calculada. Em notação matemática, as propriedades do processo estocástico estacionário podem ser representadas por: (Média) $E\left(Y_{t}\right)=\mu$, (Variância) $\operatorname{var}\left(Y_{t}\right)=E\left(Y_{t}-u\right)^{2}=\sigma^{2}$ e (Covariância) $\gamma_{k}=E\left[\left(Y_{t}-\mu\right)\left(T_{t+k}-\mu\right)\right]$. Um processo estocástico com as propriedades descritas anteriormente é conhecido, na literatura de séries temporais, como processo fracamente estacionário, ou estacionário em covariância, ou estacionário de segunda ordem, ou estacionário em sentido amplo. Um processo estocástico é fortemente estacionário quando todos os momentos de sua distribuição não variam ao longo do tempo (BUENO, 2008.)
} 
equação por Mínimos Quadrados Ordinários e pode ser expresso, conforme Enders (1995), da seguinte forma:

$$
\begin{gathered}
\Delta y_{t}=\alpha_{0}+\gamma y_{t-1}+\sum_{i=2}^{p} \beta_{i} \Delta y_{t-i+1}+\varepsilon_{t} \\
\text { com: } \gamma=-\left(1-\sum_{i=1}^{p} \alpha_{i}\right) \text { e } \beta_{i}=\sum_{j=i}^{p} \alpha_{j},
\end{gathered}
$$

em que $\alpha_{0}$ é o intercepto; $\gamma$ descreve o comportamento da série temporal; $y$ representa a variável dependente; $\Delta$ é a representação do operador de diferença e $\varepsilon_{t}$ denota o erro que se assume ser idêntica e independentemente distribuída. A fim de determinar o número de defasagens utilizadas no teste para eliminar a autocorrelação residual, utilizou-se o menor valor do critério de Schwarz (SBC).

O parâmetro de interesse nas regressões (sem intercepto e sem tendência; com intercepto; com intercepto e tendência) é $\gamma$, sendo que, se $\gamma=0$, a série contém uma raiz unitária. Nesse teste, compara-se o resultado da estatística $\tau$ com os valores apropriados reportados por Dickey-Fuller para determinar se aceita ou se rejeita a hipótese nula $\gamma=0$. A hipótese nula será rejeitada se o valor calculado da estatística $\tau$ for maior do que o valor crítico de Dickey-Fuller, indicando que a série é estacionária; caso contrário, a série é não estacionária.

O KPSS é um teste alternativo ao ADF, sendo definido pelo procedimento de um teste de não estacionariedade contra a hipótese nula de estacionariedade, conforme Greene (2008). Formalmente é expresso pela seguinte expressão:

$$
\begin{aligned}
& y_{t}=\alpha+\beta t+\gamma \sum_{i=1}^{t} z_{i}+\varepsilon_{t} \\
& y_{t}=\alpha+\beta_{t}+\gamma Z_{t}+\varepsilon_{t}
\end{aligned}
$$

tendo as seguintes hipóteses:

$H_{0}: \gamma=0$, série é estacionária

$H_{a}: \gamma \neq 0$, série é não estacionária 


\subsubsection{Análise de cointegração}

Mesmo que variáveis individuais não sejam estacionárias, mas exista pelo menos uma combinação linear estacionária entre elas, então se pode afirmar que essas variáveis são cointegradas (GREENE, 2008), ou seja, é possível verificar uma relação de equilíbrio de longo prazo entre elas, que pode ser estimada e analisada². Dessa forma, para identificar o possível relacionamento de longo prazo entre as séries, utilizou-se o teste de cointegração elaborado por Johansen (1988).

O procedimento de Johansen (1988) considera que todas as variáveis são endógenas e sua utilização não é limitada pela existência de endogeneidade do regressor (relação causal no sentido da variável dependente para a variável explicativa). Esse procedimento utiliza Máxima Verossimilhança para estimar os vetores de cointegração e permite testar e estimar a presença de vários vetores e não só de um único vetor de cointegração.

De acordo com Harris (1995), definido um vetor $z_{t}$ de $n$ variáveis potencialmente endógenas, é possível especificar o seguinte processo gerador, e modelar $z_{t}$ como um Vetor Auto-regressivo (VAR) irrestrito com $\mathrm{k}$ defasagens de $z_{t}$ :

$$
z_{t}=A_{1} z_{t-1}+\ldots+A_{k} z_{t-k}+u_{t}
$$

em que: $z_{t}$ é um vetor (nx1), $A_{i}$ é uma matriz de parâmetros (nxn) e $u_{t}$ $\sim \operatorname{IID}\left(\mu, \sigma^{2}\right)$.

Ainda conforme Harris (1995), a Equação (7) pode ser reparametrizada em termos de um modelo Vetorial de Correção de Erro (VEC) esboçado como:

$$
\Delta z_{t}=\Gamma_{1} \Delta z_{t-1}+\ldots+\Gamma_{k-1} \Delta z_{t-k+1}+\prod z_{t-k}+\varepsilon_{t}
$$

em que $\Gamma_{i}=-\left(\boldsymbol{I}-\boldsymbol{A}_{1}-\cdots-\boldsymbol{A}_{\boldsymbol{i}}\right),(\mathrm{i}=1, \ldots, \mathrm{k}-1)$ e $\Pi=-\left(\boldsymbol{I}-\boldsymbol{A}_{1}-\cdots \boldsymbol{A}_{k}\right)$. Da forma como especificado, o sistema contém informações de curto e longo prazo a mudanças de $z_{t}$, via estimativas de $\hat{\Gamma}_{i}$ e $\hat{\Pi}$, respectivamente, onde $\Pi=\alpha \beta^{\prime}$, com a representando a velocidade de ajustamento ao desequilíbrio e $\beta$ a matriz de coeficientes de longo prazo.

\footnotetext{
${ }^{2}$ Engle e Granger (1987) mostram que, se todas as séries de interesse possuem a mesma ordem de integração $I(d)$ e existir um vetor $\alpha$, com $\alpha \neq 0$, em que a combinação linear dessas variáveis seja de ordem $d-b, Z_{t}=\alpha^{\prime} X_{t} \sim I(d-b), b>0$, pode-se afirmar que $X_{t}$ é um vetor de variáveis cointegradas denotadas por $X_{t} \sim C I(d, b)$.
} 
A importância do modelo de correção de erro reside no fato de permitir a ligação entre aspectos relacionados à dinâmica de curto prazo com os de longo prazo (HAMILTON, 1994). Dessa forma, os mecanismos de correção de erro pretendem fornecer um caminho para combinar as vantagens de se modelar tanto em nível quanto nas diferenças. Nesse modelo, não apenas a dinâmica do processo de ajustamento de curto prazo como também a do processo de longo prazo são modeladas simultaneamente.

O número de vetores de cointegração depende do posto ou rank $(r)$ da matriz П. Em termos de vetores de cointegração, têm-se três possibilidades, conforme Enders (1995): se o posto de $\Pi$ é completo, então as variáveis $Y_{t}$ são I(0), ou seja, significa que qualquer combinação linear entre as variáveis é estacionária e o ajuste do modelo deve ser efetuado com as variáveis em nível; se o posto de $\Pi$ é zero, então não há relacionamento de cointegração e o modelo deve ser ajustado com as variáveis em diferença e, quando $\Pi$ tem posto reduzido, há $r$ vetores de cointegração.

Para Enders (1995), o rank de uma matriz é igual ao número de raízes características estritamente diferentes de zero, que pode ser identificado por meio de dois testes estatísticos. O primeiro deles é o teste do traço, que testa a hipótese nula de que o número de vetores de cointegração distintos é menor ou igual a $r$ contra a hipótese alternativa de que o número desses vetores é maior do que r, que pode ser definido por:

$$
\lambda_{\text {trace }}(r)=-T \sum_{i=r+1}^{n} \ln \left(1-\lambda_{i}^{i}\right)
$$

em que $\lambda_{i}^{\prime}=$ valores estimados das raízes características obtidos da matriz $\Pi$; $T=$ número de observações.

O segundo teste é o do máximo autovalor, que testa a hipótese nula de que o número de vetores de cointegração é $r$ contra a hipótese alternativa de existência de $r+1$ vetores de cointegração, podendo ser expresso da seguinte forma:

$$
\lambda_{\max }(r, r+1)=-T \ln \left(1-\lambda_{r+1}^{\prime}\right)
$$


Verificada a cointegração entre as séries analisadas, estima-se o modelo VEC, conforme definido na Expressão (8).

\subsubsection{Testes de autocorrelação}

\subsubsection{Teste de Portmanteau}

O teste de Portmanteau calcula as estatísticas Box-Pierce / Ljung-Box multivariadas para correlação serial residual até a defasagem especificada. BoxPierce (1970) desenvolveu uma estatística Q baseada na soma dos quadrados das autocorrelações. A estatística de Box-Pierce, $Q=T * \sum_{k=1}^{q} \rho_{k}^{2}$, é comparada à distribuição qui-quadrado com "q" graus de liberdade. Caso o resíduo seja um ruído branco, a estatística Q definida segue uma distribuição qui-quadrado com "q" graus de liberdade. Ljung-Box (1978), também conhecido como teste de Box-Pierce modificado, é utilizado para verificar se há falha de ajuste em um modelo temporal. 0 teste examina as " $\mathrm{n}$ " primeiras autocorrelações dos resíduos e, caso estas sejam pequenas, há indício de que não há falha no ajuste. A hipótese nula desse teste considera que as autocorrelações até o lag " $n$ " é igual a zero e a estatística do teste é definida pela Equação (11):

$$
Q^{*}=T *(T-2) \sum_{k}^{n} \frac{\hat{\rho}_{k}^{2}}{T-k}
$$

onde $\hat{\rho} k$ a autocorrelação estimada dos resíduos na defasagem " $\mathrm{k}$ " e " $\mathrm{n}$ " o número de lags testado. $O$ teste irá rejeitar a hipótese nula caso $Q^{*}>\chi_{1-\alpha ; q}^{2}$, sendo $\chi_{1-\alpha ; q}^{2}$ uma distribuição qui-quadrado com " $q$ " graus de liberdade e nível de significância $\alpha$.

\subsubsection{Teste LM}

O teste de Breusch (1978) - Godfrey (1978), também conhecido como teste LM (Lagrange Multiplier) para autocorrelação, testa a hipótese nula de ausência de autocorrelação até a defasagem $p$. Após definir o modelo e estimar seus coeficientes, o teste consiste em efetuar uma regressão do resíduo contra o próprio resíduo defasado no tempo e as variáveis explicativas, de acordo com a Equação (12):

$$
\hat{u}_{t}=\alpha_{0}+\alpha_{1} x_{t}+\hat{\rho}_{1} \hat{u}_{t-1}+\hat{\rho}_{2} \hat{u}_{t-2}+\cdots+\hat{\rho}_{p} \hat{u}_{t-p}+v_{t}
$$


onde os últimos termos $\hat{u}_{t-1}, \hat{u}_{t-2}, \ldots, \hat{u}_{t-p}$ são os resíduos estimados pela equação do modelo adotado.

\subsubsection{Fonte dos dados}

Os dados para estimação do modelo apresentado na Equação (4) foram coletados nos seguintes sites: no Centro de Estudos Avançados em Economia Aplicada - CEPEA (2019) para a variável preço de exportação do algodão (indicador do algodão CEPEA/ESALQ - à vista, em cents de dólar por libra-peso - US\$/ lb); no Instituto de Economia Aplicada - IPEA (2019), para as variáveis custo de produção, utilizado como proxy o Índice de Preços ao Atacado - Disponibilidade Interna - IPA- DI, e a taxa de câmbio nominal (em real/ dólar - R\$/US\$); e na Intercontinental Exchange ICE (2019), para a variável preço internacional do algodão (contrato futuro do algodão, primeiro vencimento, em cents de dólar por libra-peso - US\$/ lb). O período analisado foi o de junho/1999 a dezembro/2018, com cotações mensais, totalizando 235 observações. As séries também foram separadas em 2 (dois) subperíodos: 01 - de junho de 1999 a junho de 2009; e 02 - de julho de 2009 a dezembro de 2018.

Na Tabela 3, encontra-se um resumo das variáveis estimadas no modelo.

Tabela 3 -Variáveis estimadas no modelo e as respectivas siglas

\begin{tabular}{lc}
\hline Variável & Sigla \\
\hline Log preço de exportação do algodão/ período total & LBRA_A \\
Log preço de exportação do algodão / subperíodo 01 & LBRA_A01 \\
Log preço de exportação do algodão / subperíodo 02 & LBRA_A02 \\
Log custo de produção no Brasil/ período total & LBRA_CP \\
Log custo de produção no Brasil/ subperíodo 01 & LBRA_CP01 \\
Log custo de produção no Brasil/ subperíodo 02 & LBRA_CP02 \\
Log taxa de câmbio Real/ Dólar / período total & LTX_D \\
Log taxa de câmbio Real/ Dólar / subperíodo 01 & LTX_D01 \\
Log taxa de câmbio Real/ Dólar / subperíodo 02 & LTX_D02 \\
Log preço internacional do algodão / Bolsa Nova York/ período total & LINT_ANY \\
Log preço internacional do algodão / Bolsa Nova York / subperíodo 01 & LINT_ANY01 \\
Log preço internacional do algodão / Bolsa Nova York / subperíodo 02 & LINT_ANY02 \\
\hline Fonte: Organização dos autores &
\end{tabular}

Além disso, o período de análise teve seu início em junho de 1999 em função da série de preços internacionais do algodão, correspondendo ao período inicial de disponibilidade da série na ICE (2019). Já a data final está relacionada ao período de 
coleta dos dados e estimação dos modelos. Ainda, as séries preços de exportação e preços internacionais foram dessazonalizadas pelo método Exponential Smothing - ES do software Eviews 11. Na seção seguinte, é apresentada a análise e discussão dos resultados dos modelos para o algodão estimados no período total e subperíodos.

\section{ANÁLISE E DISCUSSÃO DOS RESULTADOS}

Como forma de indicar a ordem de integração das séries de análise, foram aplicados dois testes de estacionariedade: ADF - Dickey- Fuller Aumentado; e KPSS Kwiatkoswski, Philips, Schmidt e Shin. Os resultados estão expostos nas Tabelas 4 e 5.

Tabela 4 - Testes de raiz unitária em nível aplicados nas séries mensais de preços de exportação do algodão (em US\$/lb), custo de produção, taxa de câmbio nominal (R\$/ US\$) e preços internacionais do algodão (US\$/lb) no período de junho de 1999 a dezembro de 2018

\begin{tabular}{|c|c|c|c|c|c|c|}
\hline \multirow{3}{*}{$\begin{array}{l}\text { Séries } \\
\text { LBRA_A }\end{array}$} & \multicolumn{3}{|c|}{ Teste ADF } & \multicolumn{3}{|c|}{ Teste KPSS } \\
\hline & \multirow{2}{*}{$\begin{array}{c}\text { Modelo } \\
\text { constante }\end{array}$} & \multicolumn{2}{|c|}{ Estatística de teste } & \multirow{2}{*}{$\begin{array}{c}\text { Modelo } \\
\text { constante }\end{array}$} & \multicolumn{2}{|c|}{ Estatística de teste } \\
\hline & & -2.546945 & ns & & 1.097986 & $\star \star \star$ \\
\hline LBRA_A01 & constante & -2.448793 & ns & constante & 0.586200 & $\star \star$ \\
\hline LBRA_A02 & constante & -3.151004 & $\star \star$ & constante & 0.321908 & * \\
\hline LBRA_CP & constante & -2.326150 & ns & constante & 1.953265 & $\star \star \star$ \\
\hline LBRA_CP01 & constante & -1.878691 & ns & constante & 1.237602 & $\star \star \star *$ \\
\hline LBRA_CP02 & constante & -1.212090 & ns & constante & 1.229072 & $\star \star \star *$ \\
\hline LTX_D & constante & -1.310487 & ns & constante & 0.462303 & * \\
\hline LTX_D01 & constante & -1.785185 & ns & constante & 0.301445 & ns \\
\hline LTX_D02 & constante & -0.431792 & ns & constante & 1.137738 & 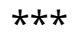 \\
\hline LINT_ANY & constante & -2.859001 & * & constante & 0.912846 & $\star \star \star$ \\
\hline LINT_ANY01 & constante & -2.488822 & ns & constante & 0.159275 & ns \\
\hline LINT_ANY02 & constante & -2.522651 & ns & constante & 0.352932 & $\star \star \star *$ \\
\hline
\end{tabular}

Pela análise da Tabela 4, observa-se que somente a série do preço de exportação do algodão no segundo período (LBRA_A02) foi estacionária em nível pelo teste ADF. Já as séries do preço de exportação do algodão no segundo período (LBRA_A02), taxa de câmbio no período total (LTX_D), no primeiro período (LTX_D01) e no segundo período (LTX_D02), e o preço internacional do algodão no primeiro período (LTX_ANY01) foram estacionárias em nível para o teste KPSS, com 5\% de significância. Por outro lado, os resultados da Tabela 5 indicam concordância em ambos os testes, pois, efetuada a primeira diferença, as séries foram estacionárias, com 5\% de significância. 
Tabela 5- Testes de raiz unitária em primeira diferença aplicados nas séries mensais de preços de exportação do algodão (em US\$/lb), custo de produção, taxa de câmbio nominal (R\$/ US\$) e preços internacionais do algodão (US\$/ lb) no período de junho de 1999 a dezembro de 2018

\begin{tabular}{|c|c|c|c|c|c|c|}
\hline \multirow{3}{*}{$\begin{array}{l}\text { Séries } \\
\text { LBRA_A }\end{array}$} & \multicolumn{3}{|c|}{ Teste ADF } & \multicolumn{3}{|c|}{ Teste KPSS } \\
\hline & \multirow{2}{*}{$\begin{array}{c}\text { Modelo } \\
\text { constante }\end{array}$} & \multicolumn{2}{|c|}{ Estatística de teste } & \multirow{2}{*}{$\begin{array}{c}\text { Modelo } \\
\text { constante }\end{array}$} & \multicolumn{2}{|c|}{ Estatística de teste } \\
\hline & & -13.90845 & 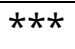 & & 0.032936 & ns \\
\hline LBRA_A01 & constante & -9.693845 & $* * *$ & constante & 0.033589 & ns \\
\hline LBRA_A02 & constante & -9.514260 & $\star \star \star$ & constante & 0.067156 & ns \\
\hline LBRA_CP & constante & -6.442072 & $\star \star \star *$ & constante & 0.456932 & * \\
\hline LBRA_CP01 & constante & -3.904573 & $\star \star \star *$ & constante & 0.401131 & * \\
\hline LBRA_CP02 & constante & -5.951036 & $\star \star \star$ & constante & 0.071804 & ns \\
\hline LTX_D & constante & -10.11407 & $\star \star \star$ & constante & 0.129286 & ns \\
\hline LTX_D01 & constante & -6.780557 & 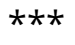 & constante & 0.209605 & ns \\
\hline LTX_D02 & constante & -7.729897 & $\star \star \star *$ & constante & 0.157063 & ns \\
\hline LINT_ANY & constante & -11.33471 & 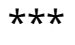 & constante & 0.029009 & ns \\
\hline LINT_ANY01 & constante & -9.357486 & $\star \star \star$ & constante & 0.034333 & ns \\
\hline LINT_ANY02 & constante & -8.240044 & $\star * \star$ & constante & 0.090037 & ns \\
\hline
\end{tabular}

Nota 1: *** significativo a $1 \%$; ** significativo a $5 \%$; * significativo a $10 \%$; ns não significativo

Fonte: Elaboração própria com base nos dados da pesquisa

Efetuados os testes de estacionariedade das séries e identificada a ordem de integração, a próxima etapa consistiu em analisar individualmente a dinâmica do repasse cambial nos preços de exportação do algodão no período total e nos dois subperíodos.

\subsection{Algodão - período total - de jun/1999 a dez/2018}

Na Figura 1, é possível identificar a evolução do preço de exportação do algodão (em US\$/lb) e a taxa de câmbio nominal (R\$/ US\$) de junho de 1999 até dezembro de 2018.

Figura 1- Relação entre preço de exportação do algodão (em US\$/ lb) e a taxa de câmbio nominal (R\$/US\$), no período de junho de 1999 a dezembro de 2018.

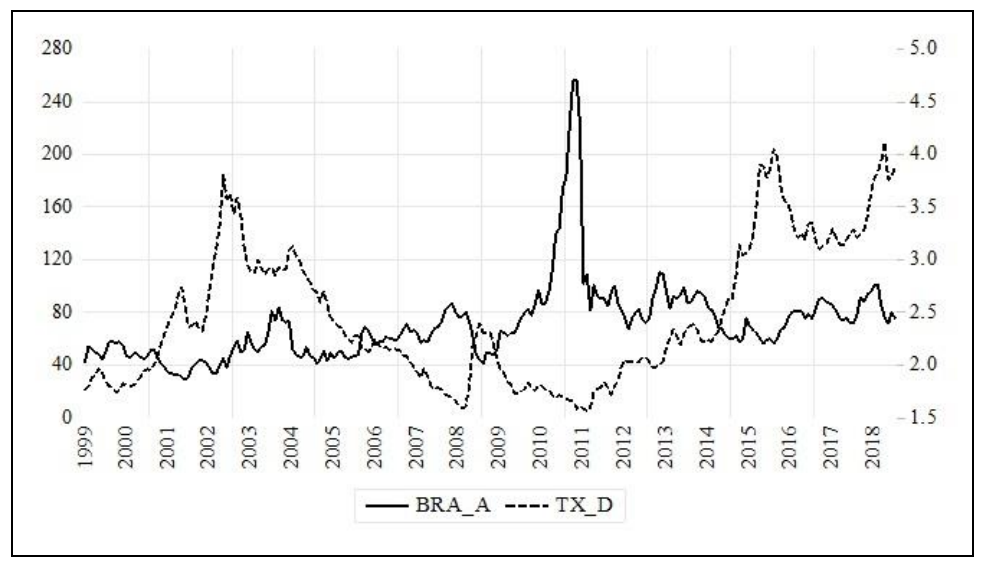


A partir da Figura 1, identificou-se que as séries apresentam uma tendência estocástica, ou seja, um padrão aleatório ao longo do tempo. Contudo, é possível que os dados apresentem um relacionamento de longo prazo a ser confirmado pelo teste de cointegração. Para realização do teste de cointegração, é necessário verificar o número de defasagens para inserir do modelo (Tabela 6).

Tabela 6 - Critério de defasagem do VAR auxiliar para o algodão - período total

\begin{tabular}{lcccccc}
\hline Defasagem & LogL & LR & FPE & AIC & BIC & HQ \\
\hline 0 & 61.90794 & NA & $7.12 \mathrm{e}-06$ & -0.501367 & -0.441759 & -0.477325 \\
1 & 1612.841 & 3034.726 & $1.20 \mathrm{e}-11$ & -13.79083 & -13.49279 & -13.67062 \\
2 & 1760.341 & 283.5067 & $3.86 \mathrm{e}-12$ & -14.92936 & $-14.39288^{*}$ & $-14.71298^{*}$ \\
3 & 1777.253 & $31.92133^{*}$ & $3.83 \mathrm{e}-12^{*}$ & $-14.93726^{*}$ & -14.16234 & -14.62471 \\
4 & 1787.717 & 19.38659 & $4.02 \mathrm{e}-12$ & -14.88932 & -13.87597 & -14.48060 \\
\hline
\end{tabular}

Nota 1: valor da verossimilhança (LogL); p-valor do teste de razão de verossimilhança (LR); Erro de Predição Final (FPE); Critério de Informação de Akaike (AIC); Critério de Informação Bayesiano de Schwarz (BIC); e o Critério de Informação de Hannan \& Quinn (HQC).

Nota 2: *indica a defasagem ótima ( $n$ ) definida pelo critério.

Fonte: Elaboração própria com base nos dados da pesquisa

Com base nos dados da Tabela 6, foi possível indicar que o número de defasagens é de 3 (três) a serem incluídas no VAR, visto que, dos cinco critérios considerados, três indicaram o mesmo número de defasagens do VAR auxiliar.

O teste de cointegração de Johansen revelou que a hipótese nula de que não há nenhum vetor de cointegração, bem como a hipótese alternativa de que há pelo menos um vetor de cointegração, devem ser rejeitadas ao nível de 5\% para a estatística do traço e para a estatística do máximo autovalor (de acordo com os dados da Tabela 7). Além disso, o modelo da equação de cointegração que mais se ajustou ao teste foi o modelo 1 do sumário do teste, com as variáveis em nível sem tendência determinística e as equações de cointegração sem interceptos.

Tabela 7 - Teste de cointegração de Johansen para o algodão - período total

\begin{tabular}{ccccc}
\hline & \multicolumn{2}{c}{ Estatística do Traço } & \multicolumn{2}{c}{ Estatística do Máximo Autovalor } \\
\cline { 2 - 5 } & Calculado & P-valor & Calculado & P-valor \\
\hline $\mathrm{R}=0$ & $54.27238^{* * *}$ & 0.0011 & $28.03237^{\star *}$ & 0.0142 \\
$\mathrm{R} \leq 1$ & $26.24001^{* *}$ & 0.0279 & $18.76753^{\star *}$ & 0.0356 \\
$\mathrm{R} \leq 2$ & 7.472480 & 0.2805 & 5.176427 & 0.4528 \\
$\mathrm{R} \leq 3$ & 2.296052 & 0.1531 & 2.296052 & 0.1531 \\
\hline
\end{tabular}

Nota: ** significativo a $5 \% \mathrm{e}$ *** significativo a $1 \%$.

Fonte: Elaboração própria com base nos dados da pesquisa 
De acordo com a Tabela 8, que apresenta o vetor de cointegração (normalizado), todos os coeficientes estimados foram significativos ao nível de 1\%.

Tabela 8- Estimativa do vetor de cointegração (normalizado) para o algodão período total

\begin{tabular}{lccc}
\hline LBRA_A (-1) & LBRA_CP $(-1)$ & LTX_D $(-1)$ & LINT_ANY $(-1)$ \\
\hline 1,0000 & $-0.254583^{* * *}$ & $0.239398^{* *}$ & $-0.686381^{* \star *}$ \\
& $(0.06487)$ & $(0.09300)$ & $(0.08252)$ \\
& {$[-3.92475]$} & {$[2.57420]$} & {$[-8.31781]$} \\
\hline
\end{tabular}

Nota I: LBRA_A = logaritmo neperiano do preço de exportação do algodão - período total (US\$/ lb); LBRA_CP = logaritmo neperiano do custo de produção - período total; LTX_D = logaritmo neperiano da taxa de câmbio - período total (R\$/ US\$); LINT_ANY = logaritmo neperiano do preço internacional do algodão - período total (US\$/ lb).

Nota 2: os valores entre parênteses referem-se ao erro padrão, e os entre colchetes, à estatística t. Nota 3: *** significativo a $1 \%$; ** significativo a $5 \%$, ns não significativo.

Fonte: Elaboração própria com base nos dados da pesquisa

Na Equação (13), é apresentado o vetor de cointegração (normalizado), indicando o relacionamento de longo prazo entre as variáveis com as respectivas elasticidades.

$$
L B R A_{-} A_{t}=+0,25 L B R A_{-} C P_{t}-0,24 L T X_{-} D_{t}+0,69 L I N T_{-} A N Y_{t}
$$

De acordo com a Equação (13), verifica-se que o coeficiente de pass-through foi incompleto, indicando que a variação da taxa de câmbio (R\$/ US\$) influencia parcialmente o preço de exportação do algodão brasileiro, ou seja, o aumento de 10\% na taxa de câmbio ocasiona uma diminuição de 2,4\% no preço de exportação do algodão.

O estudo de Souza (2018) esboçado na literatura revisada encontrou um passthrough nulo para o algodão, porém seu período de análise foi distinto do da presente pesquisa. Demais estudos revisados sobre o repasse das variações da taxa de câmbio aos preços de exportação brasileiros corroboraram o resultado de um pass-through incompleto (FERREIRA ; SANSÓ, 1999 ; CRUZ JR. ; SILVA, 2004, TEJADA ; SILVA, 2008, FRAGA ET AL.; 2008 , CORREA, 2012; COPETTI; VIEIRA E CORONEL, 2012 ; SOUZA; RANIRO; ROSA, 2018).

O resultado da presente pesquisa sugere que as depreciações cambiais produziram pouco efeito na redução do preço de exportação do algodão em dólares e na competitividade do exportador brasileiro no comércio internacional. Para Cruz Jr. \& Silva (2004), o pass-through incompleto representa que as variações na taxa de 
câmbio produzem efeitos na moeda doméstica e na lucratividade, desta forma, nos períodos de desvalorização cambial, o exportador eleva sua margem de lucro e, na valorização cambial, o exportador é forçado a comprimir sua lucratividade. Já para Fraga et al. (2008), as políticas econômicas e cambiais que visam fomentar a competitividade do exportador via desvalorização da taxa de câmbio podem não ser o melhor instrumento para elevar suas exportações quando o grau de pass-through for incompleto.

Além disso, os exportadores possivelmente adotaram uma estratégia de precificação no meio termo entre a PCP e a LCP, ou seja, parte do preço de exportação foi fixado em reais e parte em dólar. Para Knetter (1993), a estratégia PCP indica a determinação de preços pelo exportador em relação ao mercado de destino, sendo o pass-through completo, e a LCP, o mercado de destino determina o preço, sendo o pass-through nulo.

Ainda, de acordo com a Equação (13), constata-se que o aumento de $1 \%$ no custo de produção brasileiro ocasiona um aumento de 0,25\% no preço de exportação do algodão. Também foi possível inferir, com base na Equação (13), que o aumento de $1 \%$ no preço internacional do algodão determina um aumento de $0,69 \%$ no preço de exportação do algodão. O resultado encontrado na presente pesquisa sugere um coeficiente inelástico na transmissão de preços e invalida a Lei do Preço Único, que, de acordo com Mundlack e Larson (1992), diz que bens idênticos, em regiões distintas, em livre concorrência de mercado, devem ser vendidos pelo mesmo preço. O estudo de Souza (2018), revisado na literatura, também corroborou com o resultado de um coeficiente inelástico na transmissão do preço internacional do algodão ao mercado brasileiro, com o coeficiente de $-0,847$, porém seu período de análise foi distinto do usado no presente estudo. Com a finalidade de diagnóstico do modelo, foram estimados dois testes de correlação serial para os resíduos, cujos resultados encontram-se na Tabela 9. 
Tabela 9- Testes de correlação serial para os resíduos do modelo VEC para o algodão - período total

\begin{tabular}{lcccccc}
\hline & \multicolumn{3}{c}{ Teste de Portmanteau } & \multicolumn{3}{c}{ Teste LM } \\
\cline { 2 - 6 } Defasagens & Est. Q & p-valor & Est Ajust.Q & p-valor & Est. LM & p-valor \\
\hline 1 & 0.774757 & --- & 0.778125 & --- & 18.64652 & 0.2874 \\
2 & 2.209826 & --- & 2.225728 & --- & 18.07725 & 0.3194 \\
3 & 9.371094 & --- & 9.481223 & -- & 21.23453 & 0.1697 \\
4 & 17.22818 & 0.9439 & 17.47676 & 0.9386 & 12.46648 & 0.7113 \\
5 & 36.68850 & 0.7749 & 37.36762 & 0.7498 & 23.40424 & 0.1033 \\
6 & 52.50242 & 0.7433 & 53.60325 & 0.7070 & 17.82585 & 0.3342 \\
7 & 77.15086 & 0.4416 & 79.02195 & 0.3837 & 26.04471 & 0.0534 \\
8 & 102.5878 & 0.2115 & 105.3714 & 0.1610 & 26.21614 & 0.0511 \\
9 & 124.9755 & 0.1262 & 128.6667 & 0.0853 & 25.77564 & 0.0573 \\
10 & 137.6160 & 0.1903 & 141.8792 & 0.1299 & 13.68937 & 0.6218 \\
11 & 157.5369 & 0.1476 & 162.7962 & 0.0911 & 21.01398 & 0.1780 \\
12 & 167.0885 & 0.2575 & 172.8711 & 0.1685 & 9.116716 & 0.9085 \\
\hline
\end{tabular}

Fonte: Elaboração própria com base nos dados da pesquisa

Com base na análise dos dados apresentados na Tabela 9, até doze defasagens o teste indica a rejeição da hipótese nula de que a correlação serial é diferente de zero, com 5\% de significância. Desta forma, os resultados de diagnóstico do modelo estimado são válidos e apresentam um relacionamento correto e confiável entre as variáveis em questão.

Nas próximas subseções, serão apresentadas as análises em subperíodos como forma de testar a estabilidade do relacionamento da taxa de câmbio e os preços de exportação do algodão.

\subsection{Análise do subperíodo 01 - de jun/1999 a jun/2009}

Para realização do teste de cointegração, é necessário verificar o número de defasagens para inserir do modelo (Tabela 10).

Tabela 10 - Critério de defasagem do VAR auxiliar para o algodão - subperíodo 01

\begin{tabular}{lcccccc}
\hline Defasagem & LogL & LR & FPE & AIC & BIC & HQ \\
\hline 0 & 102.0477 & NA & $2.20 \mathrm{e}-06$ & -1.676029 & -1.581596 & -1.637691 \\
1 & 793.4868 & 1323.781 & $2.13 \mathrm{e}-11$ & -13.22200 & -12.74983 & -13.03030 \\
2 & 894.6512 & $186.7650^{*}$ & $4.97 \mathrm{e}-12^{*}$ & $-14.67780^{*}$ & $-13.82790^{*}$ & $-14.33275^{*}$ \\
3 & 904.8503 & 18.13171 & $5.50 \mathrm{e}-12$ & -14.57864 & -13.35100 & -14.08023 \\
4 & 912.9665 & 13.87385 & $6.32 \mathrm{e}-12$ & -14.44387 & -12.83850 & -13.79211 \\
\hline
\end{tabular}

Nota 1: valor da verossimilhança (LogL); p-valor do teste de razão de verossimilhança (LR); Erro de Predição Final (FPE); Critério de Informação de Akaike (AIC); Critério de Informação Bayesiano de Schwarz (BIC); e o Critério de Informação de Hannan \& Quinn (HQC).

Nota 2: *indica a defasagem ótima ( $n$ ) definida pelo critério.

Fonte: Elaboração própria com base nos dados da pesquisa 
Com base nos dados da Tabela 10, foi possível indicar que o número de defasagens é de 2 (duas) a serem incluídas no VAR, visto que, dos cinco critérios considerados, todos indicaram o mesmo número de defasagens do VAR auxiliar. O teste de cointegração de Johansen revelou que a hipótese nula de que não há nenhum vetor de cointegração deve ser rejeitada ao nível de 5\% (de acordo com os dados da Tabela 11). Além disso, o modelo da equação de cointegração que mais se ajustou ao teste foi o modelo 5 do sumário do teste, com as variáveis em nível com tendência quadrática e as equações de cointegração com tendência linear.

Tabela 11 - Teste de cointegração de Johansen para o algodão - subperíodo 01

\begin{tabular}{ccccc}
\hline & \multicolumn{2}{c}{ Estatística do Traço } & \multicolumn{2}{c}{ Estatística do Máximo Autovalor } \\
\cline { 2 - 5 } & Calculado & P-valor & Calculado & P-valor \\
\hline $\mathrm{R}=0$ & $56.75177^{\star *}$ & 0.0366 & $32.02390^{\star \star}$ & 0.0354 \\
$\mathrm{R} \leq 1$ & 24.72787 & 0.3998 & 12.11157 & 0.7552 \\
$\mathrm{R} \leq 2$ & 12.61629 & 0.2657 & 9.669446 & 0.4285 \\
$\mathrm{R} \leq 3$ & 2.946848 & 0.0860 & 2.946848 & 0.0860 \\
\hline
\end{tabular}

Nota: ** significativo a $5 \%$ e *** significativo a $1 \%$

Fonte: Elaboração própria com base nos dados da pesquisa

De acordo com a Tabela 12, que apresenta o vetor de cointegração (normalizado), todos os coeficientes estimados foram significativos ao nível de $1 \%$.

Tabela 12 - Estimativa do vetor de cointegração (normalizado) para algodão subperíodo 01

\begin{tabular}{lccccc}
\hline LBRA_A01 (-1) & LBRA_CP01 (-1) & LTX_D01 (-1) & LINT_ANY01 (-1) & @TREND(99M06) & C \\
\hline 1,0000 & $1.749007^{\star \star *}$ & $-0.717464^{\star \star \star}$ & $-1.088502^{\star \star \star}$ & -0.018172 & -7.902155 \\
& $(0.53176)$ & $(0.23374)$ & $(0.14422)$ & - & - \\
& {$[3.28908]$} & {$[-3.06943]$} & {$[-7.54749]$} & - & - \\
\hline
\end{tabular}

Nota I: LBRA_A01 = logaritmo neperiano do preço de exportação do algodão - subperíodo 01 (US\$/ Ib); LBRA_CP01 = logaritmo neperiano do custo de produção - subperíodo 01; LTX_D01 = logaritmo neperiano da taxa de câmbio - subperíodo 01 (R\$/ US\$); LINT_ANY01 = logaritmo neperiano do preço internacional do algodão - subperíodo 01 (US\$/ lb); @TREND(99M06) = tendência; C = constante.

Nota 2: os valores entre parênteses referem-se ao erro padrão, e os entre colchetes, à estatística t.

Nota 3: *** significativo a $1 \%$; ** significativo a $5 \%$, ns não significativo.

Fonte: Elaboração própria com base nos dados da pesquisa

Na Equação (14), é apresentado o vetor de cointegração (normalizado), indicando o relacionamento de longo prazo entre as variáveis com as respectivas elasticidades.

$$
\text { LBRA_A01 } 1_{t}=-1,75 \text { LBRA_CP01 }+ \text { + 0,72 LTX_D01 }+1,09 \text { LINT_ANY01 }+ \text { + 0,02 @TREND }(99 \mathrm{M} 06)+7,90
$$


De acordo com a Equação (14), verifica-se que o coeficiente de pass-through foi incompleto, indicando que a variação da taxa de câmbio (R\$/ US\$) influencia parcialmente o preço de exportação do algodão brasileiro no subperíodo 01, ou seja, o aumento de $1 \%$ na taxa de câmbio ocasiona um aumento de $0,72 \%$ no preço de exportação do algodão no subperíodo 01.

Ainda, de acordo com a Equação (14), constata-se que o aumento de $1 \%$ no custo de produção brasileiro ocasiona uma redução de 1,75\% no preço de exportação do algodão no subperíodo 01. Embora este resultado vá de encontro à teoria econômica, o estudo de Souza (2018) apresentou resultado de um custo de produção nulo para o algodão, indicando que o custo de produção não exerce influência sobre os preços de exportação do algodão. Além disso, observa-se, na Tabela 11, que a variável custo de produção (LBRA_CP01) apresenta baixo grau de explicação do comportamento dos preços de exportação do algodão (LBRA_A01), pois, decorridos 24 meses após um choque não antecipado sobre o preço de exportação do algodão (LBRA_A01), somente 1,64\% de seu comportamento devem-se ao custo de produção (LBRA_CP01), sendo que os 98,36\% restantes são distribuídos às demais variáveis, 14,01\% a ela própria (LBRA_A01), 13,08\% à taxa de câmbio (LTX_D01) e 71,27\% ao preço internacional do algodão (LINT_ANY01).

Tabela 13 - Resultados da decomposição da variância dos erros de previsão em porcentagem para as variáveis LBRA_A01, LBRA_CP01, LTX_D01 e LINT_CNYD01 no período de junho de 1999 a junho de 2009.

\begin{tabular}{lccccc}
\hline Variável & Período (meses) & LBRA_A01 & LBRA_CP01 & LTX_D01 & LINT_ANY01 \\
\hline LBRA_A01 & 1 & 100.0000 & 0.000000 & 0.000000 & 0.000000 \\
& 6 & 30.07876 & 0.529439 & 34.74178 & 34.65002 \\
& 12 & 17.94131 & 0.631125 & 19.83581 & 61.59175 \\
& 18 & 15.21770 & 1.365072 & 15.06974 & 68.34748 \\
& 24 & 14.00979 & 1.643143 & 13.08073 & 71.26634 \\
\hline
\end{tabular}

Fonte: Elaboração própria com base nos dados da pesquisa

Também foi possível inferir, com base na Equação (14), que o aumento de 1\% no preço internacional do algodão determina um aumento de $1,09 \%$ no preço de exportação do algodão no subperíodo 01. O resultado encontrado sugere um coeficiente elástico na transmissão de preços e valida a Lei do Preço Único. 
Com a finalidade de diagnóstico do modelo, foram estimados testes de correção serial para os resíduos, cujos resultados encontram-se na Tabela 14.

Tabela 14 - Teste de correlação serial para os resíduos do modelo VEC para o algodão - subperíodo 01

\begin{tabular}{lcccccc}
\hline & \multicolumn{3}{c}{ Teste de Portmanteau } & & Teste LM & \\
\cline { 2 - 7 } Defasagens & Est. Q & p-valor & Est Ajust.Q & p-valor & Est. LM & p-valor \\
\hline 1 & 0.707126 & --- & 0.713169 & -- & 10.90748 & 0.8152 \\
2 & 5.913968 & --- & 6.009785 & --- & 11.42826 & 0.7823 \\
3 & 15.14556 & 0.9769 & 15.48220 & 0.9729 & 11.97179 & 0.7459 \\
4 & 22.32621 & 0.9973 & 22.91480 & 0.9964 & 8.469399 & 0.9336 \\
5 & 38.14331 & 0.9876 & 39.43178 & 0.9815 & 17.05641 & 0.3820 \\
6 & 60.85637 & 0.8972 & 63.36161 & 0.8493 & 24.24539 & 0.0843 \\
7 & 78.99918 & 0.8310 & 82.64856 & 0.7469 & 19.33417 & 0.2517 \\
8 & 91.96263 & 0.8653 & 96.55481 & 0.7771 & 13.78470 & 0.6147 \\
9 & 107.6078 & 0.8526 & 113.4917 & 0.7404 & 16.63334 & 0.4097 \\
10 & 118.8694 & 0.9019 & 125.7961 & 0.7993 & 13.99222 & 0.5993 \\
11 & 135.3042 & 0.8829 & 143.9204 & 0.7468 & 19.10617 & 0.2632 \\
12 & 151.4708 & 0.8682 & 161.9173 & 0.6979 & 18.88634 & 0.2746 \\
\hline
\end{tabular}

Fonte: Elaboração própria com base nos dados da pesquisa

Com base na análise dos dados apresentados na Tabela 14, até doze defasagens o teste indica a rejeição da hipótese nula de que a correlação serial é diferente de zero, com 5\% de significância. Desta forma, os resultados de diagnóstico do modelo estimado são válidos e apresentam um relacionamento correto e confiável entre as variáveis em questão.

\subsection{Análise do subperíodo 02 - de jul/2009 a dez/2018}

Para realização do teste de cointegração, é necessário verificar o número de defasagens para inserir do modelo (Tabela 15).

Tabela 15 - Critério de defasagem do VAR auxiliar para o algodão - subperíodo 02

\begin{tabular}{lcccccc}
\hline Defasagem & LogL & LR & FPE & AIC & BIC & HQ \\
\hline 0 & 247.7753 & NA & $1.63 e-07$ & -4.276759 & -4.180752 & -4.237795 \\
1 & 861.8571 & 1174.297 & $4.53 e-12$ & -14.76942 & -14.28939 & -14.57460 \\
2 & 918.1200 & $103.6421^{*}$ & $2.24 \mathrm{e}-12^{*}$ & $-15.47579^{*}$ & $-14.61173^{*}$ & $-15.12511^{*}$ \\
3 & 931.7264 & 24.10970 & $2.34 \mathrm{e}-12$ & -15.43380 & -14.18571 & -14.92727 \\
4 & 944.4743 & 21.69374 & $2.49 \mathrm{e}-12$ & -15.37674 & -13.74462 & -14.71436 \\
\hline
\end{tabular}

Nota 1: valor da verossimilhança (LogL); p-valor do teste de razão de verossimilhança (LR); Erro de Predição Final (FPE); Critério de Informação de Akaike (AIC); Critério de Informação Bayesiano de Schwarz (BIC); e o Critério de Informação de Hannan \& Quinn (HQC).

Nota 2: *indica a defasagem ótima ( $n$ ) definida pelo critério.

Fonte: Elaboração própria com base nos dados da pesquisa 
Com base nos dados da Tabela 15, foi possível indicar que o número de defasagens é de 2 (duas) a serem incluídas no VAR, visto que, dos cinco critérios considerados, todos indicaram mesmo número de defasagens do VAR auxiliar.

O teste de cointegração de Johansen revelou que a hipótese nula de que não há nenhum vetor de cointegração deve ser rejeitada ao nível de 1\% (de acordo com os dados da Tabela 16). Além disso, o modelo da equação de cointegração que mais se ajustou ao teste foi o modelo 1 do sumário do teste, com as variáveis em nível sem tendência determinística e as equações de cointegração sem interceptos.

Tabela 16 - Teste de cointegração de Johansen para o algodão - subperíodo 02

\begin{tabular}{lcccc}
\hline & \multicolumn{2}{c}{ Estatística do Traço } & Estatística do Máximo Autovalor \\
\cline { 2 - 5 } & Calculado & P-valor & Calculado & P-valor \\
\hline $\mathrm{R}=0$ & $62.41616^{\star \star *}$ & 0.0001 & $39.49411^{\star * *}$ & 0.0002 \\
$\mathrm{R} \leq 1$ & 22.92206 & 0.0733 & 14.03199 & 0.1687 \\
$\mathrm{R} \leq 2$ & 8.890064 & 0.1756 & 8.886867 & 0.1253 \\
$\mathrm{R} \leq 3$ & 0.003197 & 0.9629 & 0.003197 & 0.9629 \\
\hline Nota: & ** significativo a 5\% e ${ }^{* *}$ significativo a 1\% \\
Fonte: Elaboração própria com base nos dados da pesquisa
\end{tabular}

De acordo com a Tabela 17, que apresenta o vetor de cointegração (normalizado), todos os coeficientes estimados foram significativos ao nível de $1 \%$.

Tabela 17 - Estimativa do vetor de cointegração (normalizado) para algodão subperíodo 02

\begin{tabular}{lccc}
\hline LBRA_A02 (-1) & LBRA_CP02 $(-1)$ & LTX_E02 $(-1)$ & LINT_ANY02 $(-1)$ \\
\hline 1,0000 & $0.020993 n s$ & $-0.032369 n s$ & $-1.042894^{* * *}$ \\
& $(0.04375)$ & $(0.05969)$ & $(0.05380)$ \\
& {$[0.47987]$} & {$[-0.54227]$} & {$[-19.3860]$}
\end{tabular}

Nota I: LBRA_A02 = logaritmo neperiano do preço de exportação do algodão - subperíodo 02 (US\$/ Ib); LBRA_CP02 = logaritmo neperiano do custo de produção - subperíodo 02; LTX_E02 = logaritmo neperiano da taxa de câmbio subperíodo 02 (R\$/ US\$); LINT_ANY02 = logaritmo neperiano do preço internacional do algodão - subperíodo 02 (US\$/ lb). Nota 2: os valores entre parênteses referem-se ao erro padrão, e os entre colchetes, à estatística t. Nota 3: *** significativo a $1 \%$; ** significativo a $5 \%$, ns não significativo.

Fonte: Elaboração própria com base nos dados da pesquisa

Na Equação (15), é apresentado o vetor de cointegração (normalizado), indicando o relacionamento de longo prazo entre as variáveis com as respectivas elasticidades.

$$
L B R A_{-} A 02_{t}=+1,04 \text { LINT_ANY02 } 2_{t}
$$


De acordo com a Equação (15), verifica-se que o coeficiente de pass-through foi nulo, indicando que a variação da taxa de câmbio não influencia o preço de exportação do algodão no subperíodo 02. O estudo de Souza (2018) também encontrou um pass-through nulo para o algodão, corroborando para este resultado. Outra pesquisa que obteve um coeficiente de pass-through nulo foi a de Copetti, Vieira e Coronel (2013), mas para o grão de soja.

Uma possível explicação para o coeficiente nulo no subperíodo 02 é que os exportadores optaram por não alterar seu preço em moeda estrangeira devido à maior instabilidade cambial que caracterizou o subperíodo. De acordo com a Tabela 18, percebe-se que a média mensal da variação cambial no subperíodo 02 foi de $0,47 \%$, aproximadamente 2,6 vezes maior do que a média da variação cambial do subperíodo 01. Para Ferreira \& Sanso (1999), o coeficiente de pass-through é uma função, dentre outros fatores, da volatilidade da taxa de câmbio que os exportadores, para preservar suas participações no comércio internacional e percebendo a instabilidade do câmbio, optam por manter seus preços em moeda estrangeira invariantes as mudanças cambiais. Por esta razão, aumentos na variabilidade da taxa de câmbio podem ser acompanhados de uma redução no coeficiente pass-through.

Em relação à estratégia de preços adotada pelos exportadores, no comparativo do subperíodo 01 em relação ao subperíodo 02, possivelmente os exportadores adotaram mais uma posição PCP do que LCP, ou seja, foi possível definir os preços mais em reais do que em dólares, indicando maior competitividade nos preços no subperíodo 01. Ainda, o maior pass-through do subperíodo $01(-0,70)$ traduziu-se no aumento do volume de exportações no subperíodo 02 e na elevação da participação de mercado das exportações de milho brasileiras.

De acordo com a Tabela 18, identifica-se, no subperíodo 01, uma tendência à equiparação do preço de exportação ao preço internacional, fato atribuído possivelmente ao ganho competitivo do maior coeficiente de pass-through no subperíodo 01. Por outro lado, a tendência do subperíodo 02 é de descolamento dos preços, caracterizado com pass-through nulo e ausência na competitividade dos preços de exportação do algodão brasileiro. 
A Tabela 18 ilustra as taxas de crescimento do preço de exportação do milho, taxa de câmbio, preço internacional do milho, estoques iniciais, importações, produção, exportações, consumo interno, estoques finais; e a média da variação mensal da taxa de câmbio, de janeiro de 2000 a dezembro de 2018.

Tabela 18 - Média preço de exportação, preço internacional e variação da taxa de câmbio

\begin{tabular}{lcccc}
\hline Período & $\begin{array}{c}\text { Média preço } \\
\text { exportação algodão } \\
\text { (US\$/lb.) }\end{array}$ & $\begin{array}{c}\text { Média preço } \\
\text { internacional do algodão } \\
\text { (US\$/lb.) }\end{array}$ & $\begin{array}{c}\text { Média \% do preço } \\
\text { exportação em relação } \\
\text { ao preço internacional }\end{array}$ & $\begin{array}{c}\text { Média da \% } \\
\text { Taxa de câmbio }\end{array}$ \\
\hline jun/99 & 0,49 & 0,52 & $-5,83 \%$ & $1 \%$ \\
2000 & 0,51 & 0,60 & $-14,58 \%$ & $1 \%$ \\
2001 & 0,38 & 0,43 & $-11,59 \%$ & $2 \%$ \\
2002 & 0,40 & 0,41 & $-2,33 \%$ & $4 \%$ \\
2003 & 0,58 & 0,60 & $-3,49 \%$ & $-2 \%$ \\
2004 & 0,60 & 0,56 & $6,94 \%$ & $-1 \%$ \\
2005 & 0,47 & 0,50 & $-6,71 \%$ & $-1 \%$ \\
2006 & 0,60 & 0,52 & $15,48 \%$ & $0 \%$ \\
2007 & 0,64 & 0,57 & $12,08 \%$ & $-2 \%$ \\
2008 & 0,72 & 0,64 & $12,32 \%$ & $3 \%$ \\
jun/09 & 0,51 & 0,48 & $5,20 \%$ & $-3 \%$ \\
\hline Total SP 01 & 0,54 & 0,53 & $1,05 \%$ & $0,18 \%$ \\
\hline jul/09 & 0,67 & $5,68 \%$ & $-2 \%$ \\
2010 & 1,05 & 0,63 & $14,33 \%$ & $0 \%$ \\
2011 & 1,51 & 0,92 & $6,82 \%$ & $1 \%$ \\
2012 & 0,81 & 1,41 & $3,41 \%$ & $1 \%$ \\
2013 & 0,94 & 0,79 & $12,48 \%$ & $1 \%$ \\
2014 & 0,81 & 0,83 & $5,14 \%$ & $1 \%$ \\
2015 & 0,63 & 0,77 & $-0,69 \%$ & $3 \%$ \\
2016 & 0,73 & 0,63 & $11,66 \%$ & $-1 \%$ \\
2017 & 0,81 & 0,66 & $11,13 \%$ & $0 \%$ \\
2018 & 0,87 & 0,73 & $4,64 \%$ & $1 \%$ \\
\hline Total SP 02 & 0,88 & 0,83 & $7,64 \%$ & $0,47 \%$ \\
\hline
\end{tabular}

Fonte: Elaboração própria com base nos dados do CEPEA (2019), ICE (2019) e IPEA (2019)

Ainda, de acordo com a Equação (15), constata-se que o custo de produção brasileiro não exerce influência sobre o preço de exportação do algodão no subperíodo 02. O estudo de Souza (2018) também encontrou como resultado a ausência na elasticidade de transmissão do custo de produção aos preços de exportação do algodão, corroborando o resultado da presente pesquisa.

Também foi possível inferir, com base na Equação (15), que o aumento de 1\% no preço internacional do algodão determina um aumento de $1,04 \%$ no preço de exportação do algodão brasileiro no subperíodo 02. 
Com a finalidade de diagnóstico do modelo, foram estimados testes de correção serial para os resíduos, cujos resultados encontram-se na Tabela 19.

Tabela 19 -Teste de correlação serial para os resíduos do modelo VEC para o algodão - subperíodo 02

\begin{tabular}{lcccccc}
\hline & \multicolumn{3}{c}{ Teste de Portmanteau } & \multicolumn{3}{c}{ Teste LM } \\
\cline { 2 - 7 } Defasagens & Est. Q & p-valor & Est Ajust.Q & p-valor & Est. LM & p-valor \\
\hline 1 & 1.769405 & --- & 1.785063 & -- & 19.40849 & 0.2481 \\
2 & 13.15648 & --- & 13.37548 & --- & 24.02722 & 0.0889 \\
3 & 28.21581 & 0.4531 & 28.84181 & 0.4206 & 23.57223 & 0.0993 \\
4 & 39.17748 & 0.6781 & 40.20210 & 0.6351 & 14.74443 & 0.5434 \\
5 & 61.76640 & 0.4128 & 63.82721 & 0.3435 & 21.18836 & 0.1714 \\
6 & 76.84212 & 0.4514 & 79.74046 & 0.3623 & 16.17223 & 0.4410 \\
7 & 91.86050 & 0.4845 & 95.74136 & 0.3740 & 15.52833 & 0.4863 \\
8 & 113.2921 & 0.3447 & 118.7905 & 0.2248 & 22.03132 & 0.1422 \\
9 & 127.9928 & 0.3847 & 134.7512 & 0.2401 & 20.09517 & 0.2160 \\
10 & 139.8993 & 0.4865 & 147.8025 & 0.3094 & 12.14175 & 0.7342 \\
11 & 162.1386 & 0.3517 & 172.4169 & 0.1746 & 22.79529 & 0.1193 \\
12 & 180.7138 & 0.3093 & 193.1774 & 0.1285 & 22.47724 & 0.1284 \\
\hline
\end{tabular}

Fonte: Elaboração própria com base nos dados da pesquisa

Com base na análise dos dados apresentados na Tabela 19, até doze defasagens o teste indicou a rejeição da hipótese nula de que a correlação serial é diferente de zero, com 5\% de significância. Desta forma, os resultados de diagnóstico do modelo estimado são válidos e apresentam um relacionamento correto e confiável entre as variáveis em questão.

\section{CONCLUSÕES}

A pesquisa investigou a influência da variação da taxa de câmbio nos preços de exportação do algodão no período total e em dois subperíodos. Nesse tocante, os resultados encontrados forneceram indicações de que o grau de pass-through da taxa de câmbio para os preços de exportação do algodão foi incompleto com os coeficientes para o período total e o subperíodo 01 de, respectivamente, 0,24 e -0,72. Já o subperíodo 02 apresentou o coeficiente de pass-through nulo.

Infere-se que os coeficientes de pass-through encontrados determinam que depreciações da taxa de câmbio não se traduzem em ganhos significativos de competitividade, já que não reduzem expressivamente os preços de exportação. 
Desse modo, como as variações cambiais determinaram reduzidos efeitos sobre a competitividade do algodão, cabe um enfoque sobre aspectos como o grau de concorrência na formação de preços desse mercado (pricing to market) e a elasticidade-preço da demanda. Logo, as características do mercado do algodão como a elevada concentração, porém com reduzido poder de mercado dos exportadores, com o crescimento da renda mundial, tem possivelmente minimizado o ajuste dos preços decorrentes de depreciações cambiais.

Entre as limitações do presente trabalho, está o fato de o coeficiente de passthrough estimado ser estático, ou seja, permitir a análise geral de período específicos de tempo, não compreendendo o dinamismo e a influência da percepção do exportador sobre os movimentos cambiais período a período na sua estratégia de precificação. Neste sentido, recomenda-se, para estudos posteriores, a aplicação do filtro de Kalman como forma de captar a dinâmica do repasse cambial. 


\section{REFERÊNCIAS}

ABRAPA - Associação Brasileira dos Produtores de Algodão. A cadeia do algodão brasileiro: safra 2016/2017: desafios e estratégias. 2017. [cited 2019 out 15]. Available from: http://www.abrapa.com.br/Documents/A\%20Cadeia\%20do\%20Algoda\%CC\%830\%20B rasileiro.pdf

BESSA FR, AMIN MM. Análise das Exportações Brasileiras do Algodão em Pluma: uma aplicação de Market-share Analysis, 1989-2004. In: XXXXVII Congresso da Sociedade Brasileira de Economia, Administração e Sociologia Rural [Internet]; 2009; Porto Alegre, RS, Brasil. 2009 [cited 2019 jan 16]. Available from: http://www.sober.org.br/palestra/13/876.pdf.

BOX GEP, PIERCE DA. Distribution of Residual Autocorrelations in Autoregressivelntegrated Moving Average Time Series Models. Journal of the American Statistical Association. 1970;v.65(332):1509-1526.

BREUSCH TS. Testing for autocorrelation in dynamic linear models. Australian Economic Papers. 1978;17(31):334-355.

BUENO RDLS. Econometria de séries temporais. São Paulo: Cengage Learning; 2008.

CEPEA - CENTRO DE ESTUDOS AVANÇADOS EM ECONOMIA APLICADA [Internet]. Piracicaba: Preços agropecuários. [cited 2019 jan 14]. Available from: https://www.cepea.esalq.usp.br/br/indicador/algodao-a-vista.aspx.

CONAB - Companhia Nacional de Abastecimento. Algodão - Conjuntura Mensal Setembro/2019. [cited 2019 out 15]. Available from: https://www.conab.gov.br/infoagro/analises-do-mercado-agropecuario-e-extrativista/analises-domercado/historico-mensal-dealgodao/item/download/28956_2caa6d3f088ee9fc8145dd3a5162e23d

COPETTI LS, VIEIRA KM, CORONEL DA. Transmissão das variações da taxa de câmbio para os preços de exportação da soja no Brasil e na Argentina. Custos e Agronegócios Online. 2012; 8(3):113-132.

COPETTI LS, VIEIRA KM, CORONEL DA. Transmissão da variação da taxa de câmbio para os preços de exportação da soja em grão: análise dos mercados dos Estados Unidos, do Brasil e da Argentina. Revista em Agronegócios e Meio Ambiente. 2013; 6(3):435-461.

COPETTI LS, CORONEL DA. Competitividade das exportações brasileiras e indianas de algodão. Revista Brasileira de Administração Científica. 2018; 9(3):25-46. 
COPETTI LS, CORONEL DA. Competitividade das exportações brasileiras e australianas de algodão: uma análise por meio de indicadores de comércio internacional. Revista Observatorio de la Economía Latinoamericana.2019; 02(1):01-21.

CORREA AL. Taxa de câmbio e preços de exportação no Brasil: avaliação empírica dos coeficientes de pass-through setoriais. Economia e Sociedade. 2012; 21(1): 61-91.

CRUZ JRJC, SILVA OM. Pass-through da taxa de câmbio nos preços de exportação dos produtos agropecuários brasileiros: 1994-2003. In: Anais do XLII Congresso brasileiro de economia e sociologia rural [Internet]; 2004; Cuiabá, MT, Brasil. 2004 [cited 2019 jan 18]. Available from: http://www.sober.org.br/palestra/12/030157.pdf.

DICKEY DA, FULLER WA. Distribution of the estimators for autoregressive time series with a unit root. Journal of the American Statistical Association. 1979;74(366):427431.

DICKEY, D. A.; FULLER, W. A Likelihood ratio statistics for autoregressive time series with a unit root. Econometrica, v.49, p.1057-1073, 1981.

ENDERS W. Applied Econometric Time Series. Nova York: John Wiley \& Sons; 1995.

ENGLE RF, GRANGER CW. Co-integration and error-correction: representation, estimation and testing. Econometrica. 1987;55(2):251-276.

FERREIRA A, SANSO A. Exchange rate pass-through: the case of Brazilian exports of manufactures. In: World Congress Of The International Economic Association [Internet]; 1999 Aug 23-27; Buenos Aires, Argentina.1999 [cited 2019 jun 20]. Available from:

http://citeseerx.ist.psu.edu/viewdoc/download?doi=10.1.1.625.1580\&rep=rep1\&type= pdf

FRAGA GJ. et al. O pass-through das variações da taxa de câmbio para os preços de exportação de soja. Revista Análise Econômica. 2008; 26(49):193-210.

FREITAS CA, FOSSATI DM, NICOLA DS. Avaliando a competitividade internacional das commodities brasileiras negociadas na BM\&F, no período de 1990-2003. In: XLIIV Congresso Brasileiro de Economia e Sociologia Rural [Internet]; 2005; Ribeirão Preto, São Paulo, Brasil. 2005 [cited 2019 jul 25]. Available from: http://www.sober.org.br/palestra/2/800.pdf.

GREENE WH. Econometrics Analysis. 6 ed. New Jersey: Pearson Education; 2008.

HAMILTON JD. Time series analysis. New Jersey: Princeton University Press; 1994.

HARRIS RID. Using cointegration analysis in econometric modelling. London: Prentice-Hall-Harvester Wheatsheaf; 1995. 
IPEA - INSTITUTO DE PESQUISA ECONÔMICA APLICADA [Internet] [cited 2019 jan 14]. Available from: http://www.ipeadata.gov.br.

ICE - INTERCONTINENTAL EXCHANGE [Internet]. Cotton historical prices [cited 2019 jan 14]. Available from: https://www.theice.com/publicdocs/futures_us_reports/cotton/Cotton\%20Historical\% 20Prices.xls

JOHANSEN S. Statistical analysis of cointegration vectors. Journal of Economic Dynamic and Control. 1988;12(2-3):231-254.

KNETTER, M. M. International comparisons of pricing to market behavior. American Economic Review. 1993; v. 83, p. 473-486.

KWIAKOWSKI D, PHILLIPS PCB, SCHMIDT P, SHIN Y. Testing the alternative of stationary against the alternative of a unit root: how sure are we that economic time series have a unit root?. Journal of Econometrics. 1992; 54(1-3):159-178.

MAIA NETO PL. Caracterização, possibilidades e limitações do mercado do algodão no Brasil [dissertation]. Caruaru: Universidade Federal de Pernambuco; 2013. $107 \mathrm{p}$.

MDIC - MINISTÉRIO DE DESENVOLVIMENTO, INDÚSTRIA E COMÉRCIO EXTERIOR [Internet]. Balança Comercial [cited 2019 sept 14]. Available from: http://www.mdic.gov.br/index.php/balanca-comercial.

MENON J. Exchange rate and import prices for a small open economy. Applied Economics. 1995; 27(3):297-301.

MUNDLACK Y, LARSON DF. On the transmission of world agricultural prices. The World Bank Review. 1992; 6(1):399-422.

OBSTFELD, M.; ROGOFF, K. Exchange rate dynamics redux. Journal of Political Economy, v. 103 (3), p. 624-660, 1995.

SOUZA DKF. 0 impacto das variações cambiais nas exportações do milho e do algodão [dissertation]. Sorocaba: Universidade Federal de São Carlos; 2018. 95 p.

SOUZA DKF, RANIRO LR, ROSA MB. Análise do pass-through da taxa de câmbio para os preços de exportação do açúcar. In: Anais do $5^{\circ}$ Congresso da Sociedade Brasileira de Economia, Administração e Sociologia Rural [Internet]; 2018; Campinas, São Paulo, Brasil. 2018 [cited 2019 jul 25]. Available from: http://icongresso.itarget.com.br/tra/arquivos/ser.8/1/8807.pdf 
TEJADA CAO, SILVA AG. 0 pass-through das variações da taxa de câmbio para os preços dos principais produtos exportados pelo Brasil. Revista de Economia e Sociologia Rural. 2008; 46(01):171-205.

USDA - UNITED STATES DEPARTMENT OF AGRICULTURE [Internet]. Custom Query [cited 2019 jul 15]. Available from: https://apps.fas.usda.gov/psdonline/app/index.html\#/app/advQuery.

USDA - UNITED STATES DEPARTMENT OF AGRICULTURE [Internet]. Cotton and Products annual. Brazil. 2018. [cited 2019 out 15]. Available from: https://apps.fas.usda.gov/newgainapi/api/report/downloadreportbyfilename?filenam e=Cotton\%20and\%20Products\%20Annual_Brasilia_Brazil_4-3-2018.pdf

USDA - UNITED STATES DEPARTMENT OF AGRICULTURE [Internet]. Cotton and Products annual. India. 2009. [cited 2019 out 15]. Available from:

https://gain.fas.usda.gov/Recent\%20GAIN\%20Publications/Commodity\%20Report_CO TTON\%20AND\%20PRODUCTS\%20ANNUAL_New\%20Delhi_India_4-20-2009.pdf

WTO - WORLD TRADE ORGANIZATION [Internet]. Tariff Analysis Online [cited 2019 jun 5]. Available from: http://tao.wto.org/ 